\title{
Investigation into corrosion-induced bond degradation between concrete and steel rebar with acoustic emission and 3D laser scan techniques
}

\author{
Fujian Tang ${ }^{1 *}$, Zhibin Lin², Hongya Qu ${ }^{3}$ and Genda Chen ${ }^{4}$
}

\begin{abstract}
Corrosion-induced bond degradation of deformed steel rebar in concrete is experimentally investigated with acoustic emission (AE) and 3D laser scan technique. Concrete specimens were fabricated and subjected to direct pullout test after being corroded to different levels. The number and width of cracks present during the corrosion tests and the pull-out tests were recorded. The energy released during the pullout tests were captured with AE probes, and the frequency characteristics was analyzed. After pullout tests, the surface morphology of corroded steel rebars was determined with a 3D laser scanner. A modified bond deterioration model was proposed and the parameters associated with the model were analyzed. Results indicated that two types of AE signals were acquired during pullout tests: concrete cracking in high frequency range of $35 \sim 41 \mathrm{kHz}$ and steel-concrete friction in low frequency range of $3 \sim 15 \mathrm{kHz}$. The bond strength and the bond-slip characteristics depend upon the level of corrosion as well as the number and width of cracks. The reduction factor of the bond-slip model exponentially decreases as a function of the average cross-sectional area loss and linearly decreases with an increase of the rib area loss.
\end{abstract}

Keywords: Reinforced concrete, Bond-slip, Corrosion, 3D laser scan, Acoustic emission

\section{Introduction}

A perfect bond between concrete and steel rebar is the basis for analysis and design of reinforced concrete (RC) structures [1]. However, this principle may not be satisfied when the bond is degraded due to material deterioration in concrete, steel or both. Corrosion of steel reinforcement is one of the main causes for RC deterioration, it reduces the cross-sectional area of reinforcing bars, weakens steel-concrete interfaces, and induces cracks in concrete cover as corrosion products expand [2-5].

\footnotetext{
*Correspondence: ftang@dlut.edu.cn

1 School of Civil Engineering, Dalian University of Technology,

Dalian 116024, Liaoning, China

Full list of author information is available at the end of the article
}

Both flexural and pullout tests have been used to investigate the influence of various factors on the corrosioninduced bond degradation between steel and concrete. Flexural tests with beams or slabs were used to simulate the anchoring condition of longitudinal reinforcement under a combined bending moment and shear force [6-8]. Due to their simplicity in comparison with flexural tests, pullout tests were more frequently reported in the literature. The factors that have been studied include concrete strength [9], concrete cover thickness [10], corrosion-induced crack width [11, 12], concrete water cement ratio [13, 14], stirrup or carbon-fiber-reinforced polymer (CFRP) confinement [15-19], recycled aggregate $[20,21]$, steel rebar diameter and deformation (plain or deformed steel rebar) [22, 23], corrosion methods [24, 25], and pre-stressing strand [26]. Use of optical fiber to study the corrosion effect on the bond strength was also 
investigated [27]. However, most of the studies pay little attention on the de-bonding process and the bond-slip characteristics during pull-out test. Moreover, the average corrosion-induced mass loss of steel rebars is used as the only index to quantify the corrosion level, which is not reasonable especially for non-uniform corrosion that usually occurs on the surface of steel rebar. In addition, all the bond strength is calculated based on the original steel bar surface instead of the real corroded steel surface as the latter could not be obtained using conventional measurements.

Over the past decades, acoustic emission (AE) technology has been widely used for structural health monitoring especially for real time detection of growing cracks [28]. Corrosion of steel reinforcement causes initiation and propagation of micro-cracks in the surrounding concrete, which can be captured by AE probes. AE has also been used for corrosion monitoring of steel rebar in concrete structures [29-31], and its accuracy to localize and characterize the corrosion damage was confirmed by $\mathrm{X}$-ray computed tomography [32]. Use of AE to assess the bond behavior of corroded smooth and ribbed rebars was also investigated [33]. Therefore, AE could be an effective tool to study the corrosion-induced bond degradation. In addition, with the aid of 3D laser scanner, accurate measurement of non-uniform corrosion occurred on the surface of steel rebar has been realized [34-36].

In this study, the effect of corrosion on the bond degradation between concrete and steel rebar is experimentally investigated with acoustic emission and 3D laser scan technique. First, concrete specimens were prepared and subjected to accelerated corrosion tests. Next, pull-out tests were performed, during which the energy released due to crack propagation was monitored by using $\mathrm{AE}$ probes. Then, the corroded steel rebars were taken out of the specimens, and the surface morphology was scanned with a 3D laser scanner. The average corrosion loss, the rib area loss, and the real surface area were determined.
Finally, the corrosion-induced bond degradation mechanism was discussed and taken into account in the development of an empirical bond-slip model.

\section{Material and methods \\ Material and specimens}

Grade 420 and No. 19 (metric unit) steel bars were used in this study. The steel bars have a nominal diameter of $19.1 \mathrm{~mm}$ and a nominal cross-sectional area of $284 \mathrm{~mm}^{2}$. The average spacing and height of bar ribs are $12.0 \mathrm{~mm}$ and $0.98 \mathrm{~mm}$, respectively. The yield strength and ultimate strength are determined to be $480 \mathrm{MPa}$ and $720 \mathrm{MPa}$, respectively.

The pullout test specimens used are $152.4 \mathrm{~mm} \times 139.7 \mathrm{~mm} \times 177.8 \mathrm{~mm}$ concrete blocks with one embedded deformed bar each as schematically illustrated in Fig. 1a. The steel rebar is located near the top face with a clear concrete cover of approximately $41.3 \mathrm{~mm}$ to replicate the application condition in RC beams. The embedment length of the steel rebar was selected to be $127 \mathrm{~mm}$, which is 6.7 times the bar diameter. To reduce the potential arching effect and end restraint, the steel rebar was encased in a $25.4 \mathrm{~mm}$ long PVC pipe (within concrete) with an inner diameter of $25.4 \mathrm{~mm}$ at both ends. The above design offered ideal bond breakers for the steel rebar that at its both ends, the steel rebar can slide freely without causing any noticeable anchoring effect on concrete. To limit the corrosion on the embedment portion and minimize the effect of PVC pipes on the pullout strength of steel bars in concrete, only the ends of PVC pipes near the embedment portion were sealed with epoxy resin. The mill scale formed on the steel rebar was thoroughly cleaned off the embedded portion by using sand blaster so that any adhered oxides were removed. A total of 18 specimens were prepared and tested, including 3 specimens for reference and 15 specimens subjected to corrosion.

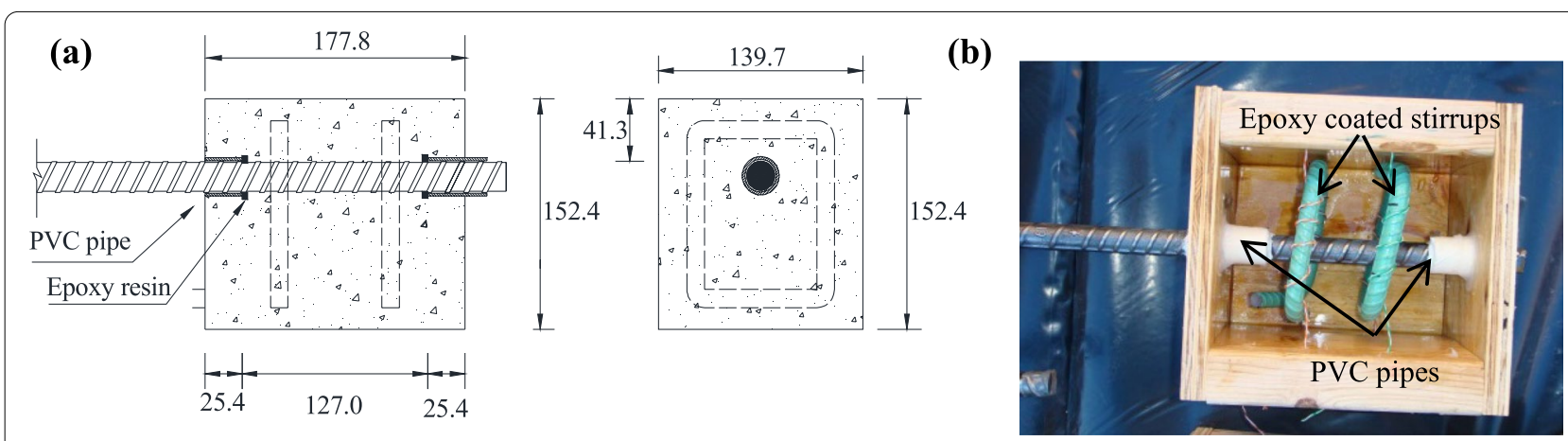

Fig. 1 (a) Pullout test specimen dimensions (unit: $\mathrm{mm}$ ), and (b) plywood mold for pullout specimen casting 
Type I Portland cement was used in this study. Limestone with a maximum diameter of $19 \mathrm{~mm}$ was used as coarse aggregate, and sand with a fineness modulus of 2.78 were used as fine aggregate. The concrete was mixed with $400 \mathrm{~kg} / \mathrm{m}^{3}$ cement, $180 \mathrm{~kg} / \mathrm{m}^{3}$ water, $740 \mathrm{~kg} / \mathrm{m}^{3}$ sand, and $1260 \mathrm{~kg} / \mathrm{m}^{3}$ limestone. The water cement ratio is 0.45 with no admixtures. At the day of pullout tests, the compressive strength and flexural strength were determined to be $32.42 \mathrm{MPa}$ and $1.62 \mathrm{MPa}$, respectively.

For the casting of concrete, formworks were constructed using $13 \mathrm{~mm}$ thick plywoods as shown in Fig. 1b. Two holes with a diameter of $28.6 \mathrm{~mm}$ were drilled on the two opposite side walls for bar placement at the predetermined location. Once the steel bar is in place, silicon resin was applied to seal the void between the holes and the PVC pipes. Two epoxy coated steel bar stirrups with a diamter of $12.7 \mathrm{~mm}$ were used as confinement. To ensure the placement of stirrups at the certain location, four palstic ties were used to mount the stirrups against the sidewalls.

\section{Accelerated corrosion test}

After air curing in room temperature for 28 days, 15 out of 18 concrete blocks were placed face to face (i.e. the surface with a cover thickness of $41.3 \mathrm{~mm}$ ) in a corrosion bath, and the space between them were filled with river sand as illustrated in Fig. 2. To create a corrosive environment, $3.5 \mathrm{wt}$.\% $\mathrm{NaCl}$ solution was sprayed every
2 days in the first 2 weeks to preserve moisture and chloride ions in the sand, and tap water was sprayed every 2 days to keep the moisture level of the river sand after 2 weeks. A constant electrical voltage of $10 \mathrm{~V}$ was applied to accelerate the corrosion process, and the steel rebar and a graphite rod with a diameter of $6.4 \mathrm{~mm}$ were respectively connected to the positive and negative ends of a power supply. During the test, the river sand was sampled for moisture measurement, and the moisture level ranged from $20 \%$ to $30 \%$. In order to monitor the electrical current through the steel rebar, one $10 \Omega$ resistor was connected in the circuit. The voltage on the resistor was recorded at an interval of 1.0 min with a DataLogger system for the determination of the electrical current flowing through each steel rebar. The corrosion-induced mass loss of steel rebar can then be evaluated by:

$$
\Delta m=\int \frac{M I d t}{z F}
$$

where $\Delta m$ is the mass of steel corroded $(\mathrm{g}), M$ is the atomic weight of the metal $(56 \mathrm{~g} / \mathrm{mol}$ for iron), $I$ is the applied current (ampere), $t$ is the time (second), $z$ is the ionic charge ( 2 for iron), and $F$ is the Faraday constant $(\mathrm{C} / \mathrm{mol})$. The time to reach the designated mass loss was calculated from Eq. (1) with the recorded corrosion current from DataLogger system. The target corrosion level in this study ranged from $0 \%$ to $35 \%$ mass loss.

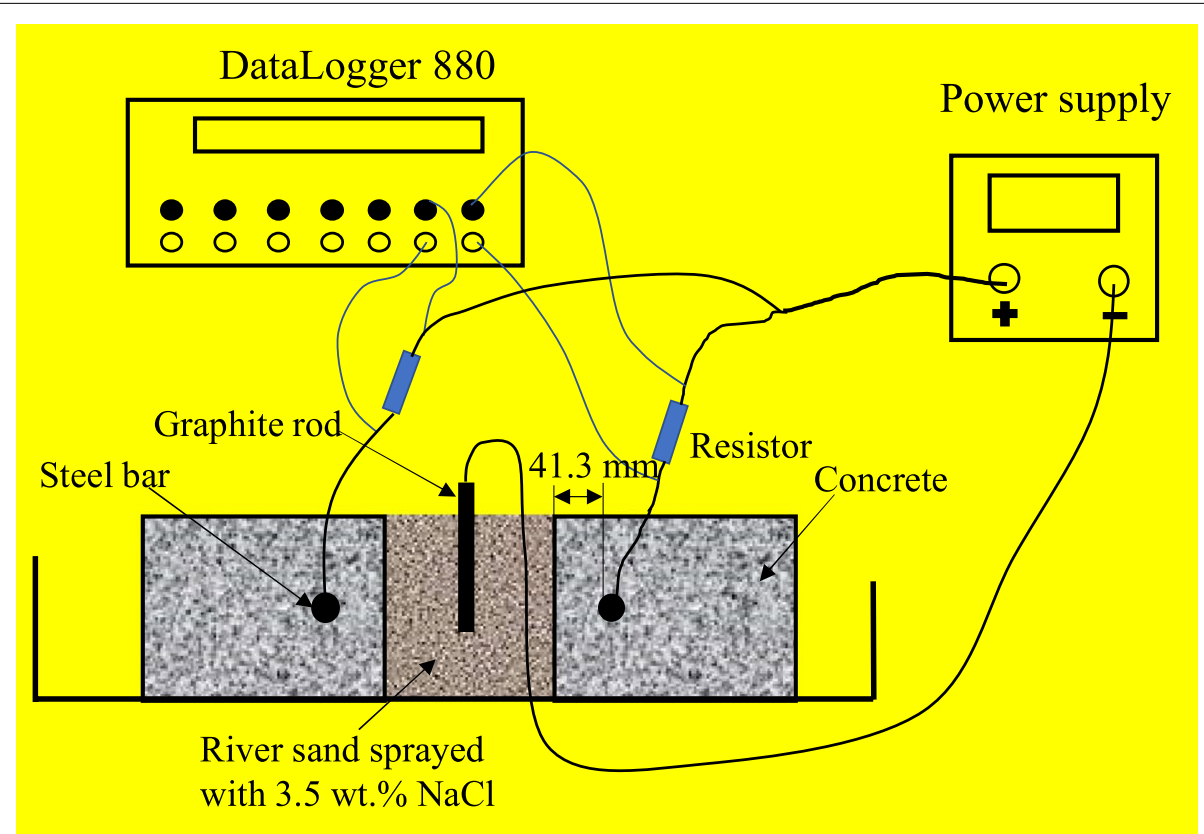

Fig. 2 Accelerated corrosion test setup 


\section{Pullout test setup}

Pullout tests were conducted on a material test machine at a loading rate of $2 \mathrm{~mm} / \mathrm{min}$, as shown in Fig. 3a with the steel rebar pulled downward. A $12.7 \mathrm{~mm}$ thick steel plate was used to provide an upward reaction to the bottom face of the concrete specimen. Between the steel plate and the concrete block was a $6.35 \mathrm{~mm}$ thick rubber pad with a center hole that was used to avoid the stress concentration caused by any potentially uneven concrete surface introduced during the casting process. To ensure that the applied force go downward without any potential eccentricity, a steel ball bearing was placed between the rubber pad and the reaction frame and the steel rebar went through the hole in the center of the ball bearing.

Each specimen was instrumented with two Linear Variable Differential Transformers (LVDTs), one was at the top end of the steel rebar (LVDT\#1) and the other was placed at the top surface of the concrete block (LVDT\#2). The LVDT\#1 used to measure the top slip of steel rebar was mounted directly on the top surface of the concrete block, and the other LVDT\#2 used to measure the concrete movement and rubber deformation was mounted on the test frame as shown in Fig. 3a. One string potentiometer was mounted around the rebar to measure the rebar elongation. Two strain gages were attached on the rebar surface to measure its strains, which would be used to calculate the rebar slip at the bottom of concrete block. The readings from the LVDTs, the string potentiometer, strain gages, and the applied load were collected through a Ni Compact Rio Data acquisition system with a sampling rate of $10 \mathrm{~Hz}$.

\section{AE test}

In order to characterize the debonding process, the acoustic signals of concrete cracking and its friction against the embedded steel rebar were recorded during the pullout tests. A 24-channel Micro-II PCI-8 module system from Physical Acoustics Corporation was used to acquire data. The acoustic sensor (Model R1.5I) used in this study incorporated a built-in low noise input, $40 \mathrm{~dB}$ preamplifier, and a filter. Its resonant frequency is $20 \mathrm{kHz}$. Three AE sensors were placed on three surfaces of each concrete block as shown in Fig. 3b. The front surface of the concrete block, closest to the steel rebar, was left for monitoring crack growth with a crack meter. Each AE sensor was fixed to a steel angle that was attached to the concrete surface with super glue and silicone grease. Such an attachment scheme can couple the AE sensor and its substrate concrete surface for an efficient transition of acoustic signals.

\section{D laser scan}

At the end of pullout tests, the concrete blocks were broken by using a steel hammer and the uncorroded/

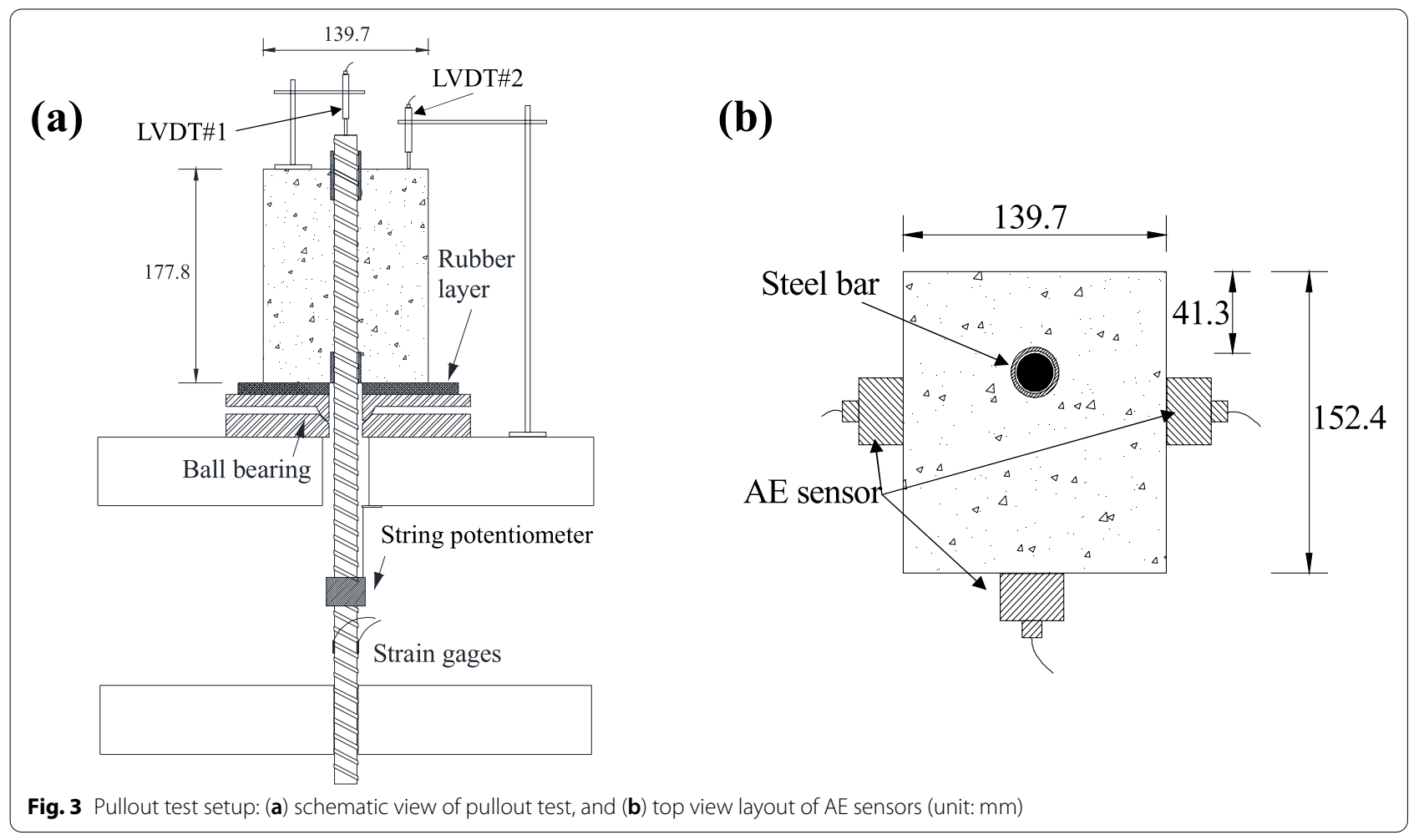


corroded steel rebars were taken out of the concrete blocks. Both the steel rebar surface and steel-concrete interface were visually examined first, and then a sand blaster was used to remove the attached concrete debris and/or corrosion products. After cleaning, the surface morphology of the embedded steel rebars was scanned using a 3D laser scanner. The scanner is capable of measuring the preferential surface profile over 360 degrees with a scan density of 36 points $/ \mathrm{mm}^{2}$. After scanning, the 3D coordinates of each point on the surface of the steel rebar were acquired and processed with ScanStudioHD software to get point cloud files with a higher signal-tonoise ratio of the data.

\section{Results and discussion}

\section{Crack pattern and opening}

The cracks induced by steel rebar corrosion were inspected prior to pullout tests and shown in Fig. 4. Four types of crack pattern were observed: one crack that propagates through the concrete cover as shown in Fig. 4a, two cracks that propagate through the two side surfaces as shown in Fig. 4b, two cracks with one propagates through the concrete cover and the other through one side surface as shown in Fig. 4c, and three cracks that propagate through both the concrete cover and the two side surfaces as shown in Fig. 4d. The appearance of different number of cracks at different locations is attributed to the non-uniform corrosion of steel rebar around both of the circumference and the length, as well as the non-homogeneity of concrete cover (i.e., spatial and size distribution of aggregates) [37, 38].

Figure 5a and c show the pullout force-slip curve and the corresponding front surface condition of specimen RE\#2 under different load levels, respectively. It can be seen in Fig. 5a that the pullout force increases rapidly in the beginning with an unnoticeable slip, which is due to combined chemical bond and mechanical interlock between steel rebar and concrete. As the pullout force increases to $65.0 \mathrm{kN}$, crack initiates at the bottom of the front surface and the force decreases slightly. With further increase of slip, the force increases again to the maximum $69.8 \mathrm{kN}$, and an obvious crack is observed on the front surface as shown in Fig. 5c. Afterwards, the pullout force decreases gradually and the crack grows higher and becomes wider with further increase of slip. The test terminated as the force decreased to $21.0 \mathrm{kN}$.

Different form the uncorroded specimen RE\#2, a corrosion-induced crack is present on the front surface of the corroded specimen C\#10 before pullout test as shown in Fig. 5d, and the corresponding pullout force-slip curve is shown in Fig. 5b. The pullout force increases rapidly with a small slip in the beginning of the test. As the force reaches $60.8 \mathrm{kN}$, a load-induced crack appears on the front surface as shown in Fig. $5 \mathrm{~d}$. In the meantime, the corrosion-induced crack becomes higher and wider. The maximum pullout force is 68.0 $\mathrm{kN}$ and it decreases slightly and remains stabilized around $60.0 \mathrm{kN}$ until the slip reaches $2.6 \mathrm{~mm}$. Afterwards, the force decreases gradually and finally stops at $16.9 \mathrm{kN}$ with a slip of around $12 \mathrm{~mm}$. Both the corrosion-induced crack and the load-induced crack gradually become higher and wider with an increase of slip throughout the pullout test.

Figure 6a shows the width of corrosion-induced cracks appeared on the front surface of concrete specimens before and after pullout test, and Fig. $6 \mathrm{~b}$ shows the increase in the crack width during the pullout test. The corrosion-induced crack width increases with an increase of corrosion loss before the test (see Fig. 6a). However, the opening of the corrosion-induced cracks decreases with an increase of the corrosion level (see Fig. 6b). This is because the height of rib decreases at high corrosion levels, resulting in a reduced mechanical interlocking action against surrounding concrete and consequently a decreased opening of surface cracks [39]. Regression analysis was performed and the fitted curves are also displayed in the figure.
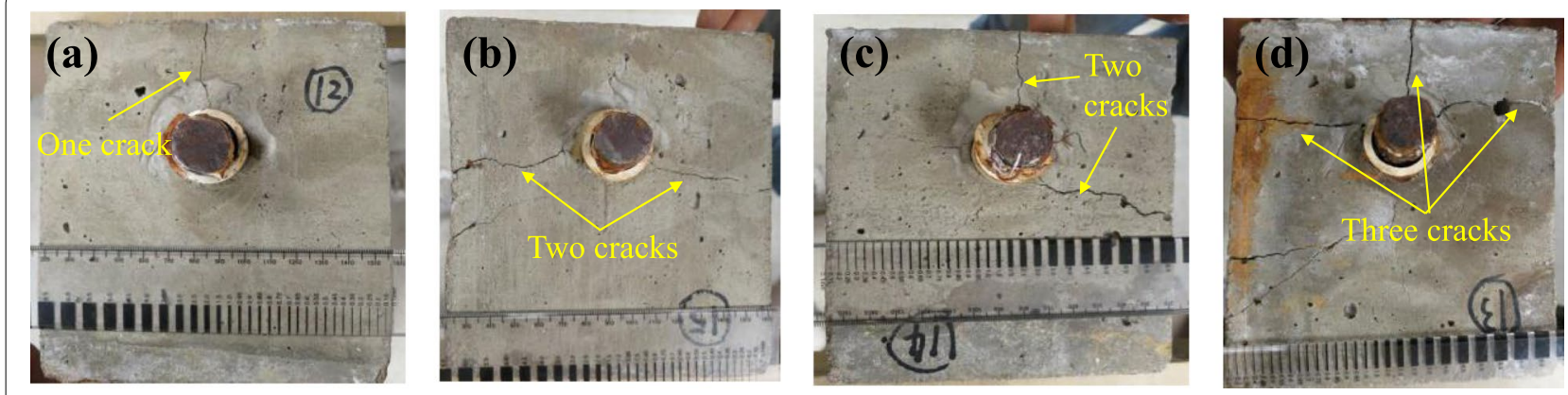

Fig. 4 Representative corrosion-induced concrete surface cracking 
(a)

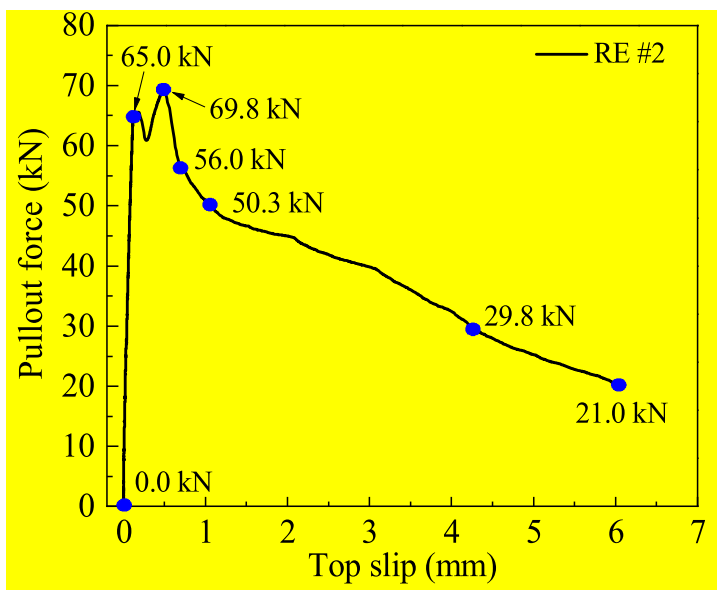

(b)

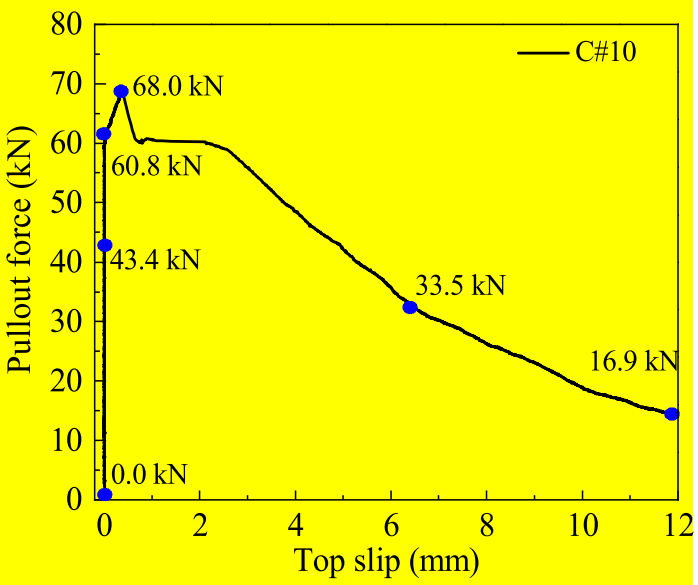

(c)

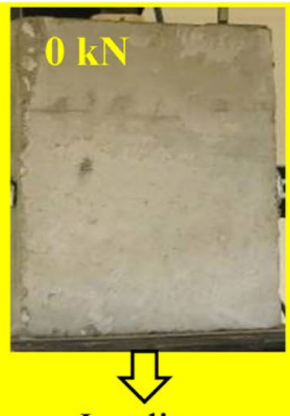

Loading

(d)

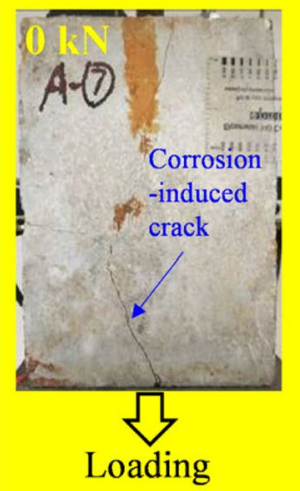

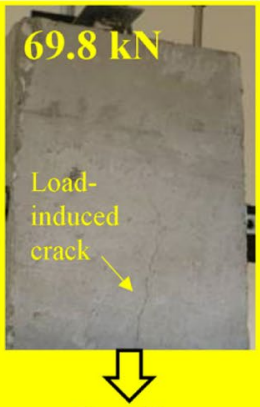

Loading

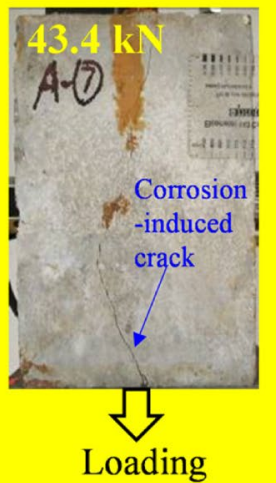

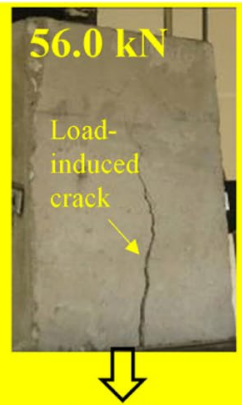

Loading

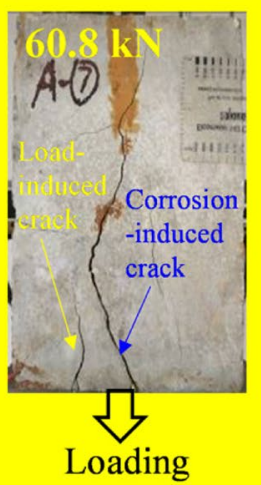

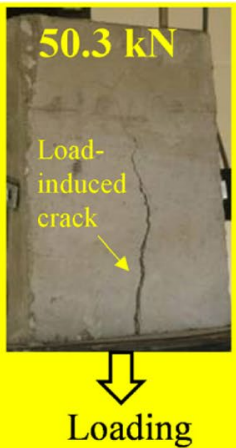

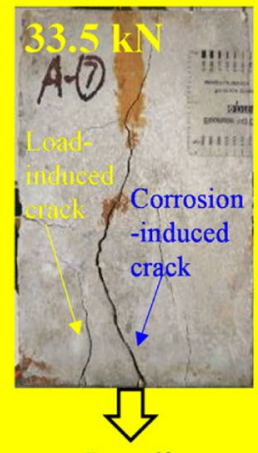

Loading

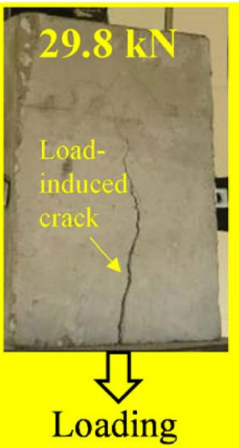

Loading

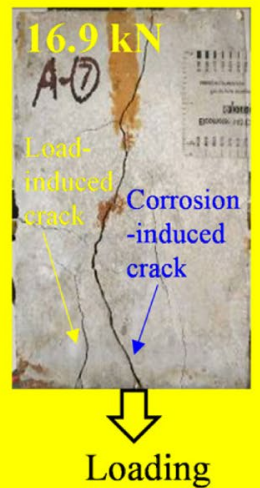

Fig. 5 Pullout force-slip curve for specimen (a) RE\#2 and (b) C\#10, and the corresponding front surface crack growth under different loading levels for (c) RE\#2 and (d) C\#10

\section{Surface morphologies and quantification of corroded steel} rebars

Figure 7 presents the scanned surface profiles of uncorroded and three corroded steel rebars with different corrosion levels. As shown in Fig. 7a, the ribs of the uncorroded rebar are periodically distributed along the length and their geometry and texture can be seen clearly. For the corroded steel rebars as shown in Figs. 7b$\mathrm{d}$, the effect of corrosion on the steel rebar surface can be clearly seen. When the corrosion loss is $7.8 \%$, a few small corrosion pits appeared on the surface do not change the ribs significantly (see Fig. 7b). When the corrosion loss reaches $15.6 \%$, a few medium size corrosion pits appear and slightly change the depth of a few ribs (see Fig. 7c). When the corrosion loss is $29.5 \%$, a few large corrosion pits appears and completely remove many ribs (see Fig. 7d).

To quantify the corrosion loss of steel rebars, the scanned 3D point cloud data was imported to ImageWare software and all the points on the steel rebar surface were 

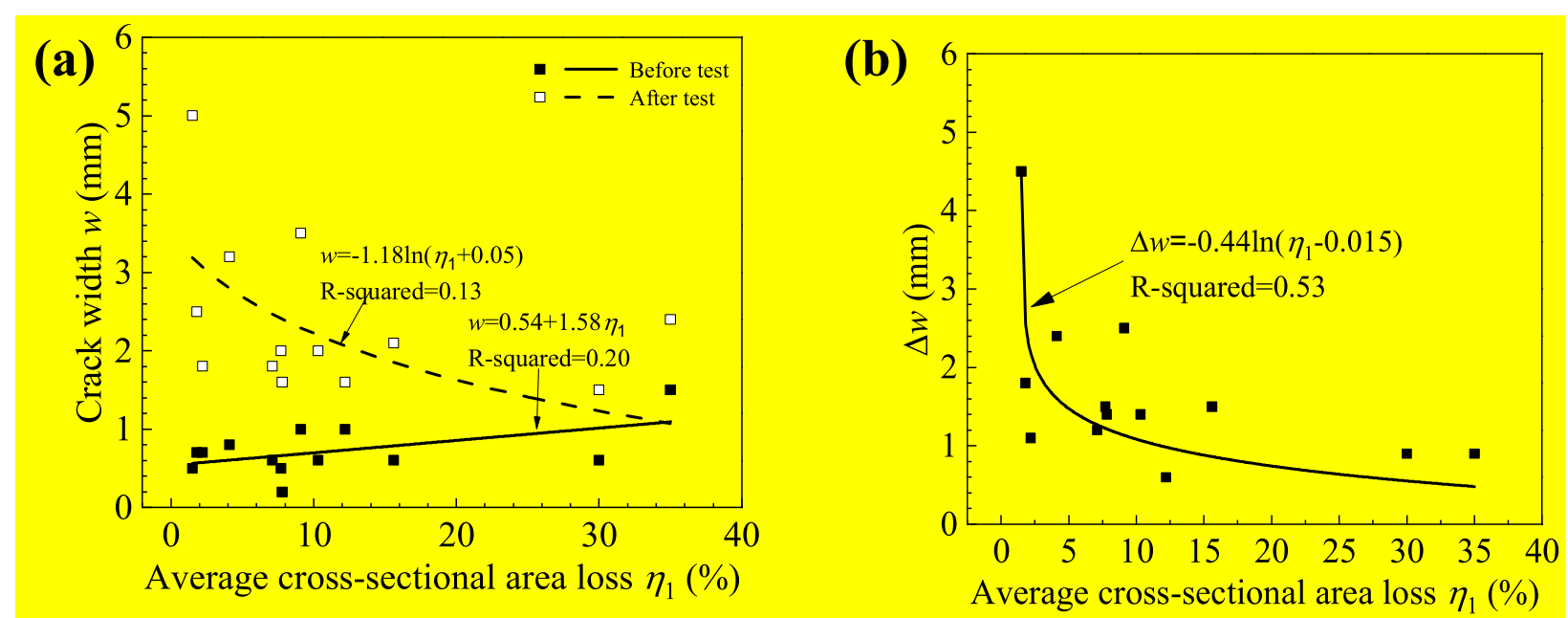

Fig. 6 (a) Corrosion-induced crack width before and after pullout test, and (b) the increase in corrosion-induced crack width during pull out test

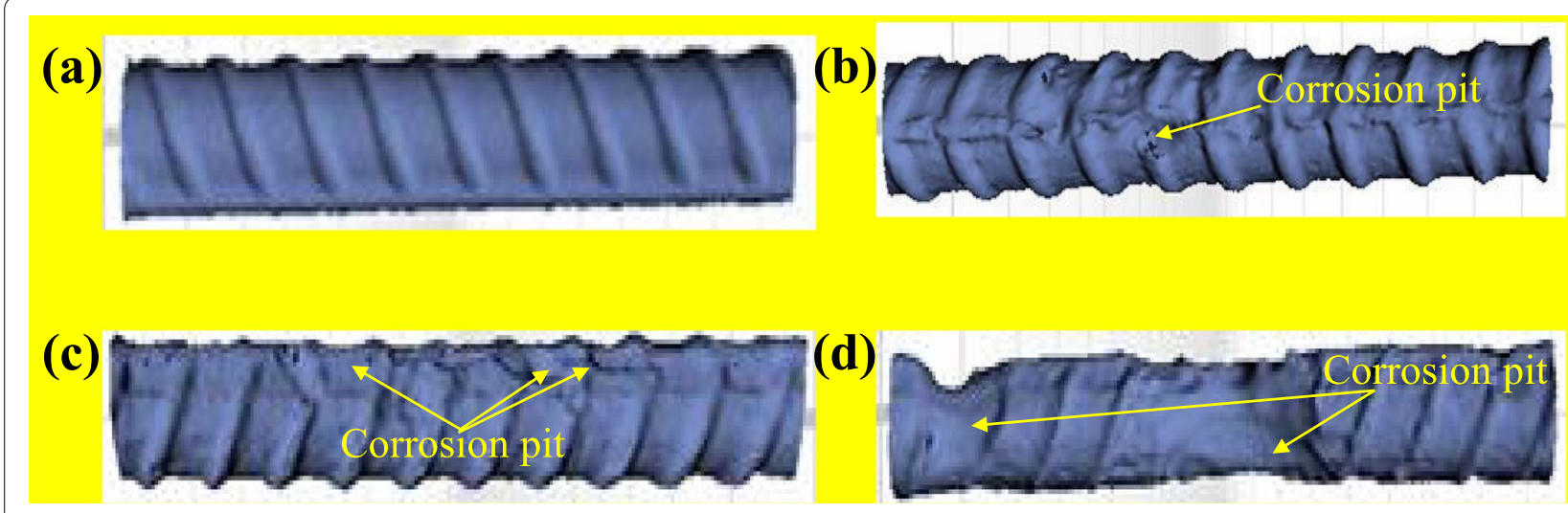

Fig. 7 Scanned 3D surface morphology of: (a) uncorroded rebar RE\#2, (b) corroded rebar C\#7( $\left.\eta_{1}=7.8 \%\right)$, (c) corroded rebar C\#11 ( $\left.\eta_{1}=15.6 \%\right)$, and (d) corroded rebar C\#14 ( $\left.\eta_{1}=29.5 \%\right)$

aligned along the centerline of the steel rebar. For crosssectional view, planes perpendicular to the centerline of the steel rebar were inserted along the length of the steel rebar at $1.0 \mathrm{~mm}$ spacing. All the points within $0.2 \mathrm{~mm}$ distance to each plane were projected to the plane. The projected points on the plane formed a polygon, which was considered as the cross section cut from that plane. The residual cross-sectional area of the corroded steel rebar corresponding to the $j$-th plane is the area of the polygon, which can be calculated by:

$$
A_{c, j}=0.5 \sum_{i=0}^{n-1}\left(x_{i} y_{i-1}-x_{i+1} y_{i}\right)
$$

where $x_{i}$ and $y_{i}$ are the coordinate of each projected point on the plane, and $n$ is the number of projected points. The average residual cross-sectional area along the embedded length can be obtained by

$$
A_{\mathrm{avg}}=\frac{1}{m} \sum_{j=1}^{m} A_{c, j}
$$

where $m$ is the total number of planes cut along the embedded length. Then the average cross-sectional area loss was calculated by using the following equation:

$$
\eta_{1}=\left(1-A_{\mathrm{avg}} / A_{0}\right) \times 100 \%
$$

where $A_{0}\left(=284 \mathrm{~mm}^{2}\right)$ is the nominal cross-sectional area of uncorroded steel rebar.

As mentioned before, the rib plays an important role in the bond strength. Therefore, the rib area loss is also determined. Figure 8 shows a typical cross section of steel rebar before and after corrosion test, which is enclosed by the scanned points. The rib area is defined as the area that has a radius greater than the radius of rebar lug $r \geq r_{0}$, and $r_{0}=9.5 \mathrm{~mm}$ for steel rebar used in this study. 

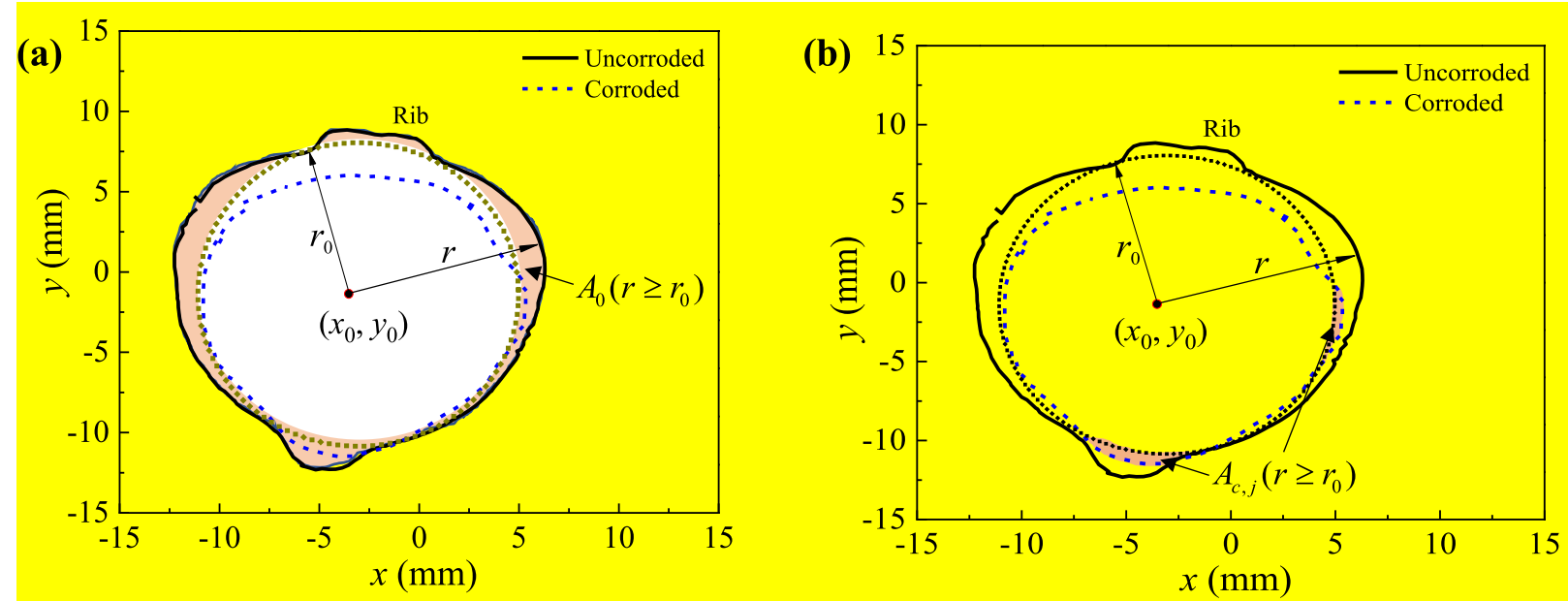

Fig. 8 Schematic illustration of (a) rib area before corrosion $A_{0}\left(r \geq r_{0}\right)$ and (b) residual rib area after corrosion $A_{c, j}\left(r \geq r_{0}\right)$

The rib area before and after corrosion is indicated by the shaded area as shown in Fig. $8 \mathrm{a}$ and b, respectively. The average rib area of corroded rebar along the embedded length is

$$
A_{\mathrm{avg}}\left(r \geq r_{0}\right)=\frac{1}{m} \sum_{j=1}^{m} A_{c, j}\left(r \geq r_{0}\right)
$$

where $r$ is the distance from the center $\left(x_{0}, y_{0}\right)$ to the points at the circumference of the scanned cross section as shown in Fig. 8, $A_{c, j}\left(r \geq r_{0}\right)$ is the residual rib area of the $j$-th cross-sectional polygon for corroded rebar as shown in Fig. 8b. Then the rib area loss is expressed as:

$$
\eta_{2}=\left[1-A_{\text {avg }}\left(r \geq r_{0}\right) / A_{0}\left(r \geq r_{0}\right)\right] \times 100 \%
$$

where $A_{0}\left(r \geq r_{0}\right)$ represents the area of ribs for uncorroded cross section which is indicated by the shaded area in Fig. 8a, and it is calculated by using:

$$
A_{0}\left(r \geq r_{0}\right)=0.5 \sum_{i=0}^{n-1}\left(x_{i} y_{i-1}-x_{i+1} y_{i}\right)-\pi r_{0}^{2}
$$

where $x_{i}$ and $y_{i}$ are the coordinates of points that consist of the cross-sectional polygon of uncorroded steel rebar. Both the average area loss and the rib area loss for steel rebars embedded in all specimens are calculated and shown in Table 1.

The width of cracks appeared on the surface of all specimens was measured by using a concrete crack width gauge and given in Table 1. For each specimen, crack width along a crack was sampled every $1.0 \mathrm{~mm}$ spacing, and therefore the mean value and standard deviation of each crack are provided as shown in Table 1.
The corrosion damage is classified into three categories as shown in Table 2 according to the number and width of crack as well as the average cross-sectional area loss, which will be correlated to the characteristics of bondslip curves.

\section{Load-slip curves}

The bond stress was calculated based on the embedded surface area of an uncorroded steel rebar to simplify the calculation of bond stress as follows:

$$
\tau=P /\left(\pi d_{b} l_{d}\right)
$$

where $\tau$ is the bond stress, $P$ is the applied load, $l_{\mathrm{d}}$ is the embedment length, and $d_{\mathrm{b}}$ is the nominal diameter $\left(d_{\mathrm{b}}=19.1 \mathrm{~mm}\right)$. As mentioned previously, the bar slip at the top of concrete block (top slip, i.e. the relative slip between the rebar and the top surface of concrete) was directly measured with LVDT\#1. The rebar slip at the bottom of concrete block (bottom slip, i.e. the relative slip between the rebar and the bottom surface of concrete) was determined based on the following equation:

$$
\delta=\Delta_{s}-L \varepsilon_{s}-\Delta_{R}
$$

where $\Delta_{\mathrm{S}}$ is the elongation of steel bar measured from the string potentiometer, $L$ is the distance from the bottom face of the specimen to the strain potentiometer, $\varepsilon_{\mathrm{s}}$ is the strain of the steel rebar, and $\Delta_{\mathrm{R}}$ is the deformation of the rubber layer which was recorded from the LVDT\#2 mounted on the top frame of the test machine.

Figure 9 shows the load-deformation curve in rubber layer, load-strain curve in steel rebar, and load-slip curves at the top and bottom of concrete blocks for specimen C\#6 during the pullout test. As indicated in Fig. 9a, the 
Table 1 Corrosion levels and cracks on the concrete surface

\begin{tabular}{|c|c|c|c|c|c|c|c|}
\hline \multirow[t]{2}{*}{ Specimen } & \multirow{2}{*}{$\begin{array}{l}\text { Average area } \\
\text { loss } \eta_{1}(\%)\end{array}$} & \multirow{2}{*}{$\begin{array}{l}\text { Rib area loss } \\
\eta_{2}(\%)\end{array}$} & \multicolumn{3}{|c|}{ Crack widths before pullout tests (mm) } & \multirow[b]{2}{*}{ Total width } & \multirow{2}{*}{$\begin{array}{l}\text { Damage } \\
\text { rating } \\
\text { (Table 2) }\end{array}$} \\
\hline & & & Front face & Left side face & Right side face & & \\
\hline C\#1 & 1.5 & 10.0 & $0.31 \pm 0.17$ & $0.32 \pm 0.17$ & - & 0.63 & moderate \\
\hline C\#2 & 1.8 & 11.2 & $0.34 \pm 0.12$ & - & - & 0.34 & slight \\
\hline C\#3 & 2.2 & 7.10 & $0.50 \pm 0.11$ & $0.25 \pm 0.09$ & - & 0.75 & moderate \\
\hline C\#4 & 4.1 & 11.8 & $0.42 \pm 0.14$ & - & - & 0.42 & moderate \\
\hline C\#5 & 7.1 & 34.0 & $0.39 \pm 0.10$ & - & - & 0.39 & slight \\
\hline C\#6 & 7.7 & 40.0 & $0.30 \pm 0.14$ & $0.48 \pm 0.24$ & $1.39 \pm 0.47$ & 2.17 & severe \\
\hline C\#7 & 7.8 & 30.4 & - & $0.44 \pm 0.16$ & $1.20 \pm 0.05$ & 1.64 & severe \\
\hline C\#8 & 9.1 & 37.5 & $0.64 \pm 0.12$ & $0.76 \pm 0.22$ & - & 1.40 & moderate \\
\hline C\#9 & 10.3 & 48.8 & $0.21 \pm 0.11$ & $0.30 \pm 0.16$ & - & 0.51 & moderate \\
\hline C\#10 & 12.2 & 58.4 & $0.26 \pm 0.09$ & $0.27 \pm 0.13$ & - & 0.53 & moderate \\
\hline C\#11 & 15.6 & 70.1 & $0.24 \pm 0.15$ & $0.87 \pm 0.43$ & $1.56 \pm 0.51$ & 2.67 & severe \\
\hline C\#12 & 17.8 & 71.2 & $0.84 \pm 0.30$ & $1.14 \pm 0.55$ & - & 1.98 & severe \\
\hline C\#13 & 18.1 & 72.1 & $1.07 \pm 0.44$ & $1.00 \pm 0.33$ & $1.28 \pm 0.92$ & 3.35 & severe \\
\hline C\#14 & 29.5 & 90.4 & $0.26 \pm 0.18$ & $1.71 \pm 0.84$ & $1.51 \pm 0.66$ & 3.48 & severe \\
\hline C\#15 & 35.0 & 93.5 & $0.98 \pm 0.30$ & $0.78 \pm 0.19$ & $0.79 \pm 0.32$ & 2.55 & severe \\
\hline
\end{tabular}

Table 2 Ratings of corrosion-induced damage

\begin{tabular}{llll}
\hline Rating & $\begin{array}{l}\text { Average } \\
\text { corrosion } \\
\text { mass loss }\end{array}$ & $\begin{array}{l}\text { Numbers } \\
\text { of Cracks }\end{array}$ & Total crack width \\
\hline Slightly damaged & $<7 \%$ & 1 & $<0.5 \mathrm{~mm}$ \\
Moderately damaged & $7 \% \sim 12 \%$ & 2 & $0.5 \sim 1.5 \mathrm{~mm}$ \\
Severely damaged & $>12 \%$ & 2 or 3 & $>1.5 \mathrm{~mm}$ \\
\hline
\end{tabular}

rubber layer shows a typical nonlinear elastic behavior, and two distinct regions can be observed. As the deformation is smaller than $0.15 \mathrm{~mm}$, the load increases slowly with the increase of the deformation. This is because the lateral deformation of rubber has just been developed and is increased with the increase of the compressive displacement. Subsequently, the load increases more rapidly as the deformation increases, which is due to the fact that the inner self-contact deformation strengthened the overall axial stiffness [40]. When loaded to the critical value $\sim 50 \mathrm{kN}$, it started to decrease. The maximum deformation in rubber layer corresponding to the maximum load was measured to be $\sim 0.28 \mathrm{~mm}$. In the unloading process, fluctuation is observed due to the cracking and crushing of concrete bottom surface above the rubber layer. Different from the rubber layer, the relation between the applied load and the rebar strain is linearly elastic as displayed in Fig. 9b. This is because the maximum pullout load applied to the specimen is significantly lower than the yield load of the steel rebar.

Figure 9c shows the load-slip curves of corroded specimen C\#6. There are two curves, one is with the slip between the top end of the steel rebar and the top surface of concrete (i.e., the top slip measured from
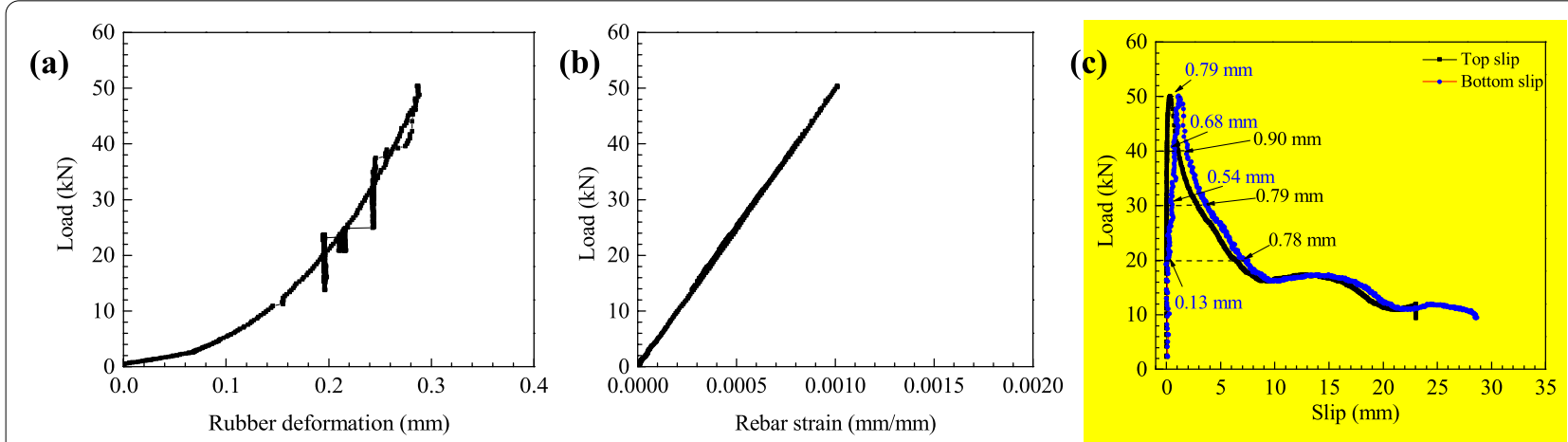

Fig. 9 Representative curves for specimen C\#6: (a) load-deformation in rubber layer, (b) load-strain in steel rebar, and (c) load-slip 
LVDT\#1), and the other is with the slip where the steel rebar exits out of concrete (i.e., the bottom slip calculated from Eq. (9)). The bottom slip is always greater than the top slip under the condition of reaching the same load because the bottom slip represents the accumulative deformation over the embedment length. It can be seen from Fig. 10c that the load increases rapidly in the beginning of the pullout test and reaches the maximum $\sim 50 \mathrm{kN}$ as the top slip is around $1.0 \mathrm{~mm}$. Afterwards, the load decreases sharply to $16 \mathrm{kN}$ and
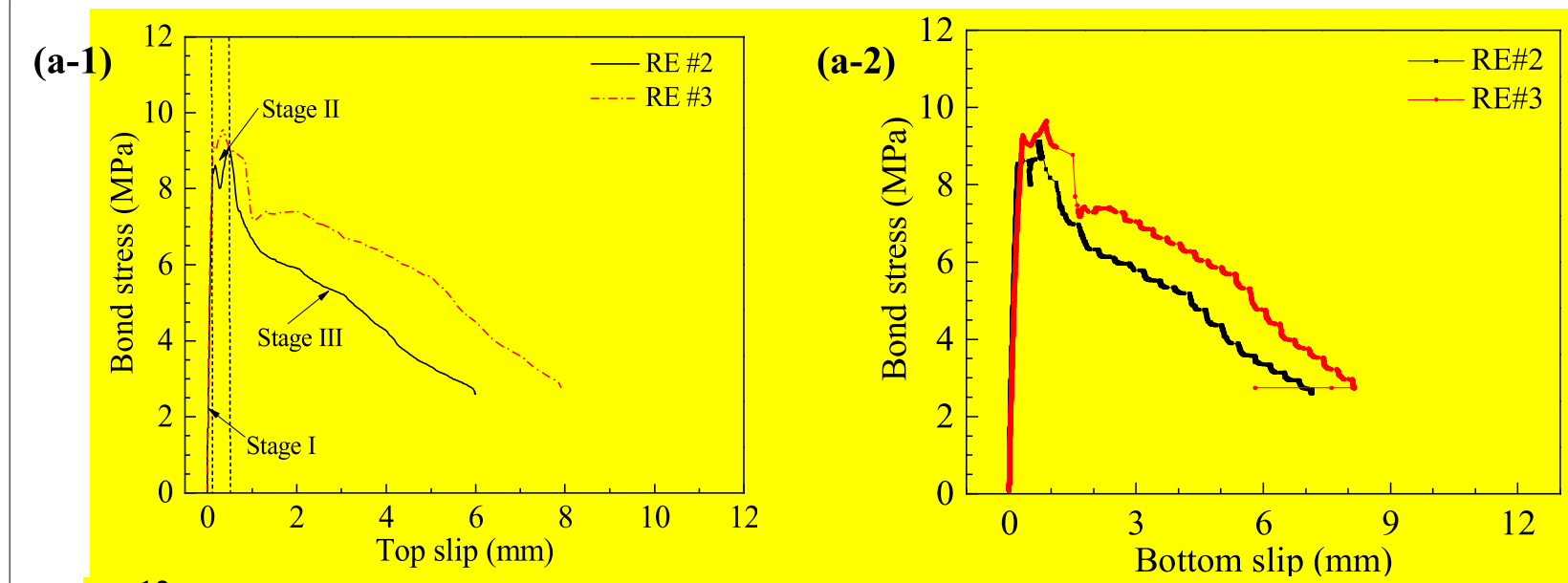

(b-1)

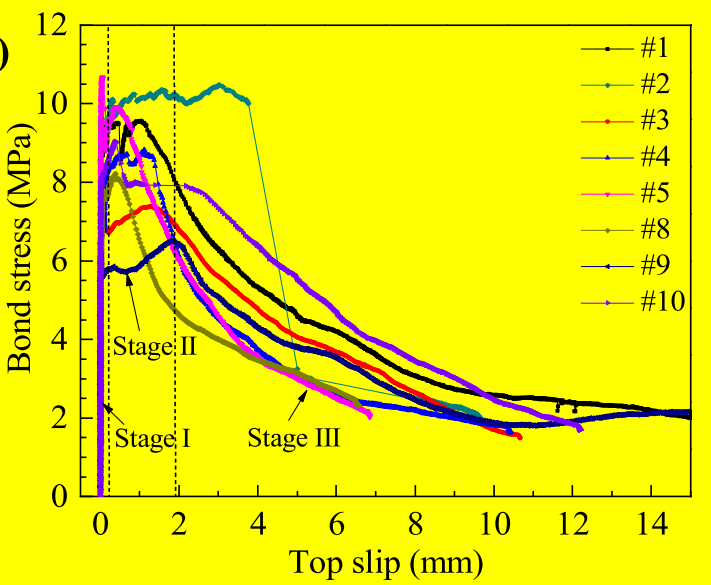

(b-2)

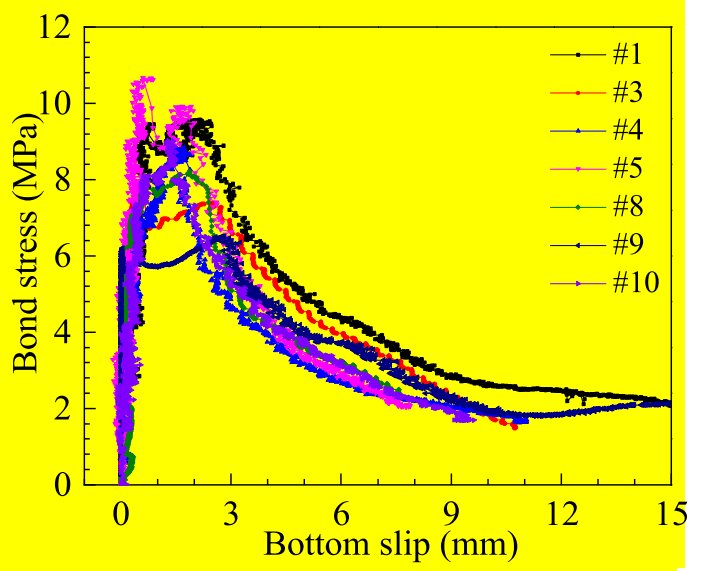

(c-1)

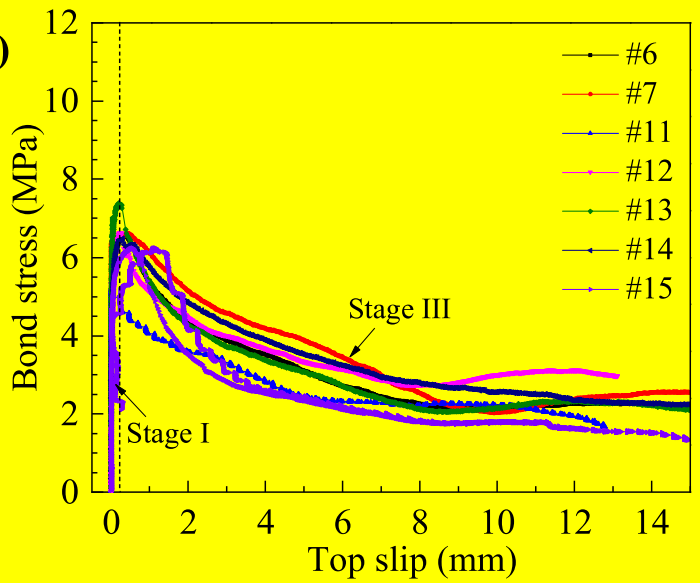

(c-2)

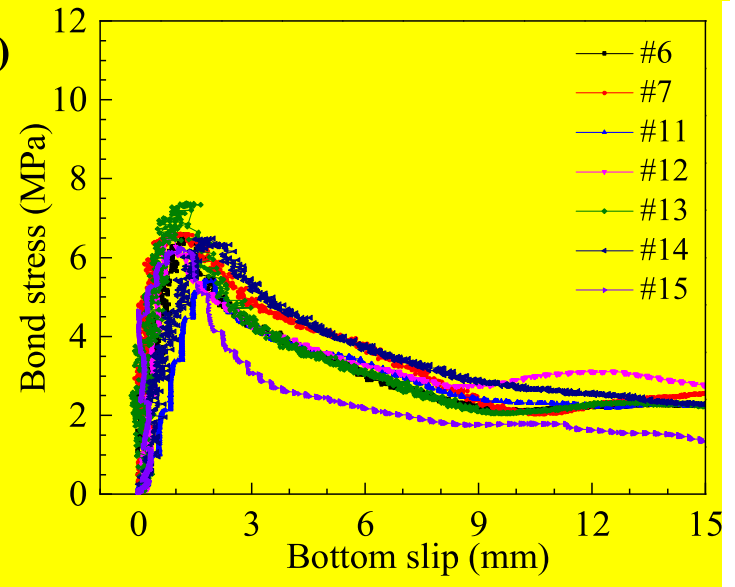

Fig. 10 Bond stress-slip (1: top slip; 2: bottom slip) curves for (a) uncorroded specimens, (b) slightly and moderately corroded specimens, and (c) severely corroded specimens 
the corresponding top slip reaches $9.0 \mathrm{~mm}$, which approximately equals to the rib spacing of the steel rebar. As the test proceeds, the load first increases slightly and then decreases gradually to $12 \mathrm{kN}$ and the corresponding slip is around twice of the rib spacing. It is noted that the difference between the two slips under the same loading force varies with the loading process as shown in Fig. 9c. The slip difference increases from $0.13 \mathrm{~mm}$ to $0.79 \mathrm{~mm}$ as the pullout force increases from $20 \mathrm{kN}$ to $50 \mathrm{kN}$ in the loading process, and reaches the maximum $0.90 \mathrm{~mm}$ as the load decreases to $40 \mathrm{kN}$. Afterwards, the difference between the two slips gradually become smaller and smaller.

Figure 10 plots the bond stress as a function of the top or bottom slip for all specimens. The bond stressslip curves based on the bottom slip are not smooth especially in the descending portion, which is due to concrete crushing as mentioned before with Fig. 9a. All the specimens are divided into three groups based on the number and width of cracks appeared on the concrete surfaces as well as the average corrosion level as classified in Table 2. Only the results of two reference specimens are presented because testing of the first specimen was terminated due to the inappropriate parameter setup. As shown in Fig. 10(a-1), the bond stress-slip curve for the specimens with uncorroded steel rebars can be broadly divided into three stages. In stage I, the bond stress, that is mainly from chemical bond and mechanical interlock between steel rebar and concrete, rapidly increases with an increase of slip. In stage II, the internal cracks induced by steel rib sliding propagate to the concrete surface, and the bond stress becomes stabilized. In stage III, cracks reduce the concrete confinement and the bond stress gradually decreases with an increase of slip. The bond stress slip curves based on the bottom slip as shown in Fig. 10(a-2) show similar trend as those based on top slip. However, the slopes of the ascending portion of all curves in stage I are greater based on the top slip than those based on the bottom slip due to the accumulated effect of steel rebar deformation at the bottom of concrete. Regarding the slightly and moderately corroded specimens as indicated in Fig. 10b, they exhibit the same behavior as the specimens with uncorroded steel rebars and three obvious stages can also be observed. Moreover, the maximum bond stress decreases slightly in comparison with those of uncorroded specimens. For most of the severely corroded specimens as shown in Fig. 10c, stage II disappears and only stage I and stage III are observed. In addition, the maximum bond stress decreases significantly. This is because the corrosion products of steel rebar expand and change the interfacial zone between concrete matrix and rebar significantly.

\section{Bond degradation}

Figure 11a shows the relationship between the average cross-sectional area loss and the average rib area loss for corroded steel rebars. Nonlinear regression analysis was performed and result shows the rib area loss exponentially increases with an increase of the average crosssectional area loss. However, the increase rate of rib area loss $\eta_{2}$ is gradually decreased as the average area loss $\eta_{1}$ increases. When the average cross-sectional area loss reaches around 35\%, all the ribs are completely corroded. This is obvious that the ribs are the outer layer of a steel rebar and corrosion would occur first on the rib area before it penetrates deep into the core area.

Figures $11 \mathrm{~b}$ shows the relationship between the maximum bond stress and the average cross-sectional area loss of steel rebar, and it can be observed that the maximum bond stress decreases with an increase of the average area loss $\eta_{1}$, which is consistent with results in [23]. Nonlinear regression analysis was performed and exponential decay function shows a satisfactory fitting. Similarly, the maximum bond stress decreases with an increase of the rib area loss $\eta_{2}$ as shown in Fig. 11c. Different from exponential decay for the average area loss $\eta_{1}$, a linear function better describes the relationship between the maximum bond stress and the rib area loss $\eta_{2}$. Figure $11 \mathrm{~d}$ shows the change of the maximum bond stress with an increase of the crack width appeared on the concrete surface, and it can be observed that the maximum bond stress gradually decreases with an increase of the average crack width.

In a study conducted by Zhao et al. [20], it is concluded that corrosion has no influence on the bond stress for concrete specimens reinforced with stirrups, which is different from the observation in this study. This is because the maximum corrosion loss of steel rebar and the maximum crack width observed in [20] is $3.99 \%$ and $0.58 \mathrm{~mm}$, respectively, which are significantly lower than the maximum corrosion loss $30 \%$ and the maximum crack width $3.48 \mathrm{~mm}$ investigated in this study. At low levels of corrosion, the interlocking between the ribs of the steel rebar and the surrounding concrete does not change very much, and the stirrups provide lateral confinement even cracks appear in the concrete. However, at higher levels of corrosion, the diminished steel ribs reduce the mechanical interlocking between steel rebar and surrounding concrete, and the bond stress consequently decreases.

Figures 11e shows the corrosion effect on the difference of slips at top and bottom concrete faces, and the slip difference increases with an increase of either average area 

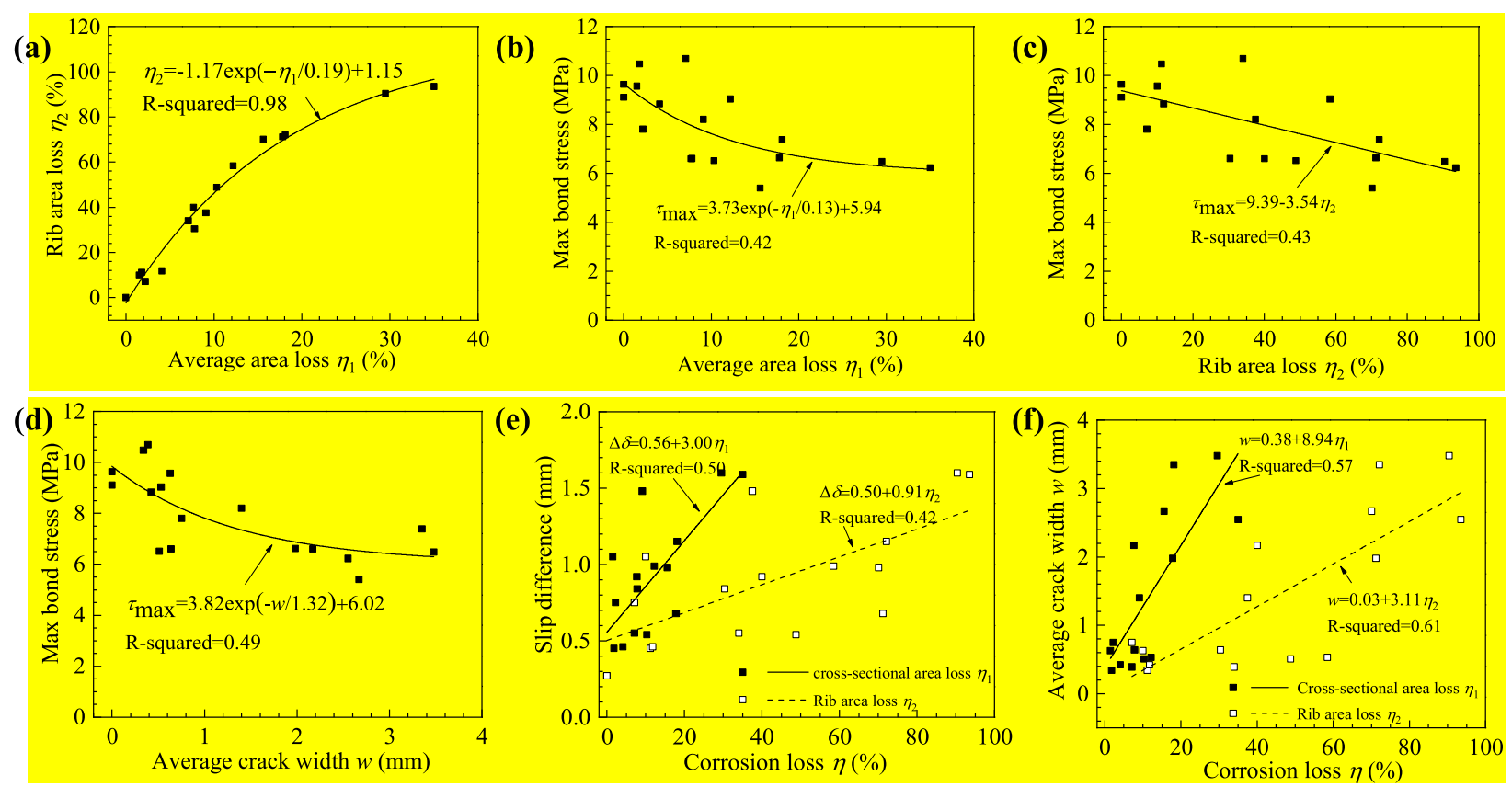

Fig. 11 Relationships between (a) rib area loss and the average area loss, (b) the maximum bond stress and the average area loss, (c) the maximum bond stress and the rib area loss, (d) maximum bond stress and average crack width, (e) top-bottom slip difference and average area loss, and (f) average crack width and average corrosion loss

loss or rib area loss. This is because corrosion reduces the cross-sectional area of steel rebar embedded in the concrete, and part of the embedded steel rebar may yield and produces significant deformation. Linear regression analysis was performed and the fitted curves and equations are also displayed in Fig. 11e. Figure 11f shows the relationship between the width of cracks on the concrete surface and the corrosion loss in terms of both the average cross-sectional area loss and the rib area loss. It can be seen that the crack width increases with an increase of either cross-sectional area loss or rib area loss, which agree well with observations in $[17,20]$.

\section{AE results}

During pullout tests, the acoustic signals were collected by $\mathrm{AE}$ sensors and they are divided into three parts according to the three stages as shown in Fig. 10. Figure 12 presents the acoustic energy spectra for three representative specimens, and two dominant frequency peaks are identified from each of the three acoustic energy spectra in three stages. The high frequency peak reflects concrete cracking and the low frequency indicates the interfacial friction between steel rebar and surrounding concrete during the pullout tests [33, 41]. As observed in Fig. 12, the energy released in stage I due to
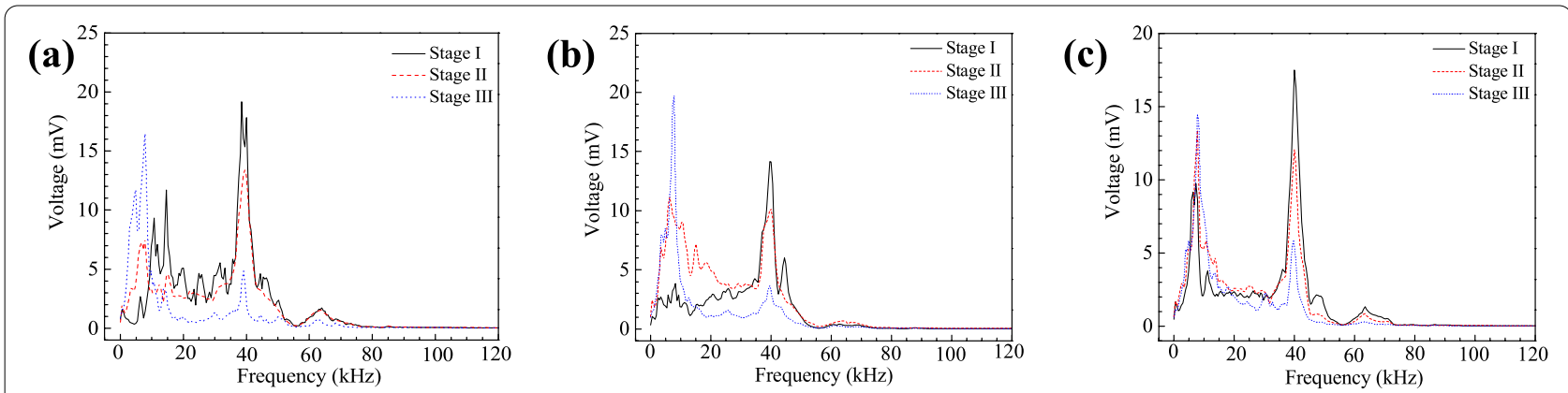

Fig. 12 Acoustic energy spectra of representative specimens with: (a) uncorroded rebar (RE\#2), (b) corroded rebar (C\#1), and (c) corroded rebar (C\#8) 
concrete cracking is generally higher than that from the friction. In contrast, the energy released in stage III from the steel-concrete friction is higher than that from concrete cracking. In stage II, the energy levels released from concrete cracking and steel-concrete friction are generally comparable. This is because stage $I$ is the process of crack initiation and propagation in concrete, while stage III corresponds to the interfacial sliding between steel rebar and surrounding concrete. As shown in Fig. 12, the friction generated acoustic energy is mainly distributed in a low frequency range of $3 \sim 15 \mathrm{kHz}$, and the cracking generated acoustic energy concentrates in a high frequency range of $35 \sim 41 \mathrm{kHz}$.

The dominant frequency ranges of seven representative specimens in stages I and III are presented in Table 3. For each specimen, three sets of signals were collected from three AE sensors, and therefore the mean value and standard deviation based on these three signals are given in Table 3. It can be clearly seen from Table 3 that the frequencies identified in stage I for concrete cracking are almost the same for concrete specimens with or without corrosion. This is because for corroded specimens, corrosion-induced cracks would propagate and new cracks would also generate in stage I during the pullout test as shown in Fig. 5d. However, the effect of corrosion on the dominant frequency can be observed in stage III due to steel-concrete friction. As indicated in Table 3, the specimen with uncorroded steel rebars had a much higher friction-associated frequency $(12.04 \mathrm{kHz})$ than those with corroded steel rebars. This is because the uncorroded specimens have significantly harder steel-concrete interfaces for the propagation of friction-induced acoustic wave than those with corroded steel rebars. The average friction frequency is around $8 \mathrm{kHz}$ for the specimens with corroded steel rebars as shown in Table 3.

\section{Characteristics of deteriorated bond-slip curve}

At the end of pullout tests, representative specimens with various levels of corrosion damage were inspected

Table 3 Frequencies in $\mathrm{kHz}$ identified during pullout tests

\begin{tabular}{lll}
\hline Specimen & Stage I: concrete cracking & $\begin{array}{l}\text { Stage III: } \\
\text { steel-concrete } \\
\text { friction }\end{array}$ \\
\hline RE\#2 & $39.71 \pm 1.227$ & $12.04 \pm 2.255$ \\
C\#1 & $40.04 \pm 0.489$ & $7.975 \pm 0.282$ \\
C\#6 & $39.71 \pm 0.282$ & $7.486 \pm 1.409$ \\
C\#7 & $40.04 \pm 0.489$ & $7.812 \pm 1.760$ \\
C\#8 & $39.71 \pm 0.564$ & $8.138 \pm 0.746$ \\
C\#12 & $39.88 \pm 0.746$ & $8.138 \pm 0.746$ \\
C\#15 & $40.36 \pm 0.746$ & $7.812 \pm 0.108$ \\
\hline
\end{tabular}

visually. Figures 13a-d present the photos of concrete and steel surfaces of uncorroded, slightly corroded, moderately corroded, and severely corroded specimens, respectively. Crushed concrete can be observed on the ribs of uncorroded rebar as shown in Fig. 13(a-2). For the slightly corroded specimen as shown in Fig. 13b, rib deformation can be seen on the concrete surface and some crushed concrete retained on the rebar ribs. For the moderately corroded specimen, some ribs completely corroded away and were left on the concrete surface as displayed in Fig. 13c. For the severely corroded specimen, all the ribs were corroded away and left on the concrete surface. In this case, a relatively smooth surface and a trace of friction can be observed in Fig. 13(d-2).

\section{Modeling of deteriorated bond-slip}

The model developed for specimens with uncorroded steel bars by [42-44] was modified to take into account the corrosion effect in this study. This model divides the bond-slip curve into three portions: the ascending portion in stages I, the stable portion in stages II, and the descending portion in stage III as indicated in Fig. 10. The model is mathematically expressed as:

$$
\tau / \tau_{0}= \begin{cases}\phi\left(s^{\prime} / s_{1}\right)^{\alpha} & 0 \leq s^{\prime}<s_{1} \\ \phi & s_{1} \leq s^{\prime}<s_{2} \\ \phi s^{\prime} /\left[\beta\left(s^{\prime}-s_{2}\right)^{2}+s^{\prime}\right] & s_{2} \leq s^{\prime} \leq 1\end{cases}
$$

where $\tau$ is the bond strength of each specimen, $\tau_{0}$ is the bond strength of uncorroded specimen at stage II, $\phi$ is the reduction factor, $s=s / \mathrm{d}_{r}$ is the normalized slip by rib spacing $\left(d_{\mathrm{r}}=12.0 \mathrm{~mm}\right.$ in this study), $s_{1}$ is the normalized slip at which stage II begins, $s_{2}$ is the normalized slip at which stage III begins, $\alpha$ is related to the slope of ascending portion in stage $\mathrm{I}, \beta$ is associated with the slope of the descending portion in stage III. Figure 14 compares the measured bond-slip curves and the fitted curves based on the modified model in Eq. (10) for several specimens, and it can be seen that the modified model in Eq. (10) can be used successfully to describe the bond-slip relation of corroded steel rebar with concrete.

The parameters in Eq. (10) were extracted based on the fitted bond-slip curves and they are listed in Table 4. It is noted that the parameters $\alpha$ based on the bottom slip are greater than these based on the top slip. This is because $\alpha$ is related to the slope (bond rigidity) in the ascending portion, and the bottom slip is always greater than the top slip at the same load level due to accumulated deformation. However, no trend is observed for parameter $\beta$. The values of both parameters $s_{1}$ and $s_{2}$ based on the bottom slip are greater than those based on the top slip, which is also attributed to the accumulated effect. For 

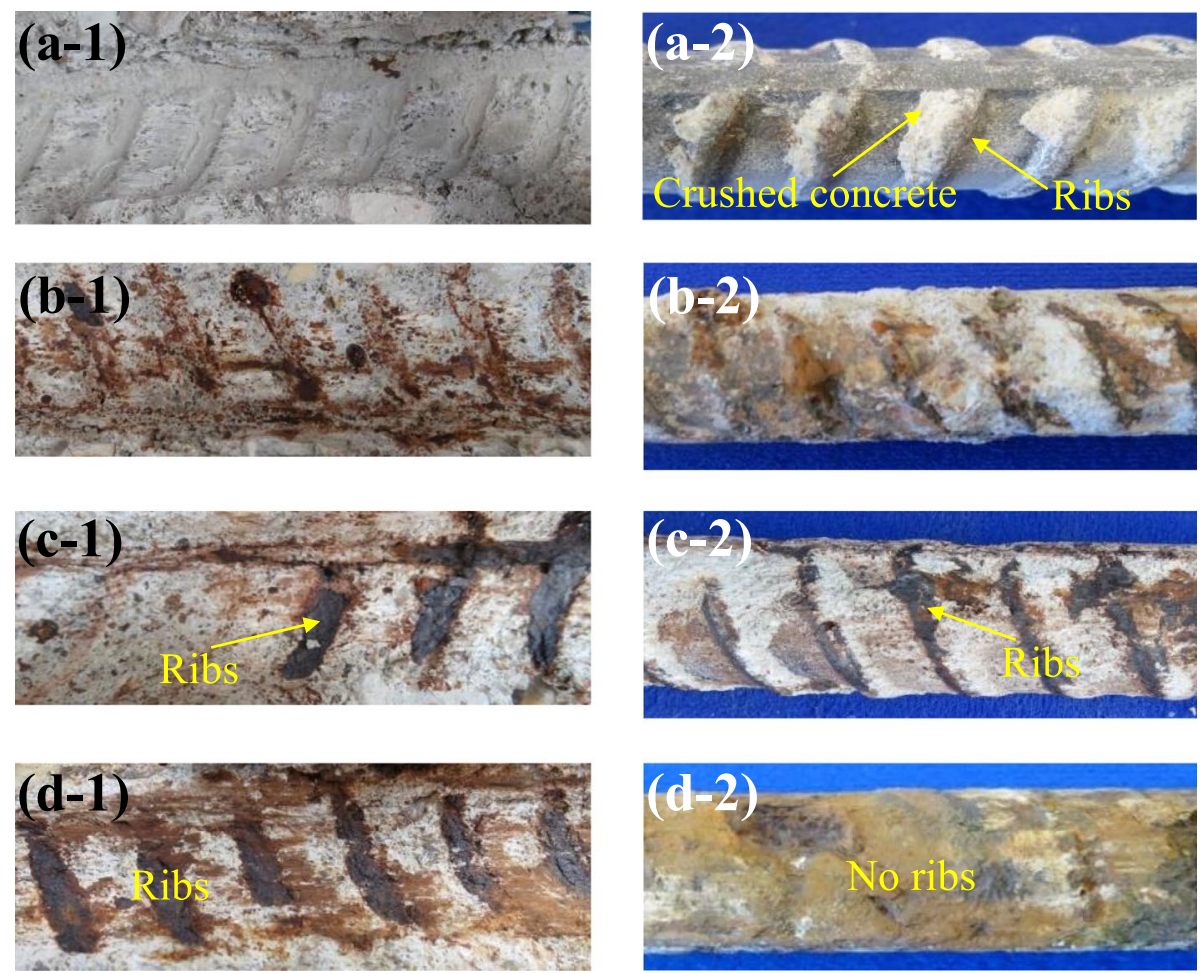

Fig. 13 Visual observations on steel-concrete interfaces after pullout tests: (1) concrete interface, (2) steel rebar surface; (a) uncorroded rebar, (b) slightly corroded rebar, (c) moderately corroded rebar, and (d) severely corroded rebar

slightly and moderately corroded specimens, $s_{2}$ is always greater than $s_{1}$, and a stable plateau appears. However, for severely corroded specimens, $s_{1}$ equals to $s_{2}$ due to absence of stages II as shown in Fig. 10c.

Figure 15 shows the relationship between the reduction factor $\phi$ and the corrosion loss of steel rebar in terms of the average cross-sectional area loss (Fig. 15a) and the rib area loss (Fig. 15b). It can be observed that the reduction factor decreases with an increase of both average area loss and rib area loss. Regression analysis was performed, and fitting results show that the reduction factor exponentially decreases as a function of the average cross-sectional area loss, while linearly decreases as the average rib area loss increases.

Figure 16 shows the recommended values of $\alpha$ and $\beta$ based on different corrosion levels for convenient engineering applications, and the corrosion levels of steel rebar are divided into five groups. It is noted that both $\alpha$ and $\beta$ are based on the measured bottom slip and the average cross-sectional area loss $\eta_{1}$. The values of $\alpha$ and $\beta$ do not change significantly as the corrosion loss is higher than $5.0 \%$ as indicated in the circled area. Therefore, for the purpose of simplicity, the corrosion levels are re-grouped into three levels as indicated in the inset table in the figure: $\eta_{1}=0, \eta_{1}=0 \sim 5.0 \%$ and $\eta_{1}>5.0 \%$. For uncorroded steel bars $\left(\eta_{1}=0\right), \alpha=0.68, \beta=3.40$ are recommended. For steel rebars with corrosion-induced area loss ranging from $0 \%$ to $5.0 \%$, recommended values of $\alpha=0.54$ and $\beta=7.07$ are provided. For steel rebars with cross-sectional area loss higher than $5.0 \%, \alpha=0.38$ and $\beta=5.90$ are recommended.

\section{Conclusions}

In this study, the corrosion effect on the characteristics of steel-concrete bond-slip curves is experimentally investigated with acoustic emission and 3D laser scan technique, and an empirical bond-slip model is developed. Based on the results and discussion, the following conclusions can be drawn:

(1) Two types of acoustic emission signals were acquired during pullout tests: concrete cracking in high frequency range of $35 \sim 41 \mathrm{kHz}$ and steelconcrete interfacial friction in low frequency range of $3 \sim 15 \mathrm{kHz}$. The frequency characteristics of friction-induced acoustic signals in stage III is affected by steel rebar corrosion: $12 \mathrm{kHz}$ is identified for concrete specimens with uncorroded steel rebars and $8 \mathrm{kHz}$ for specimens with corroded steel rebars. 

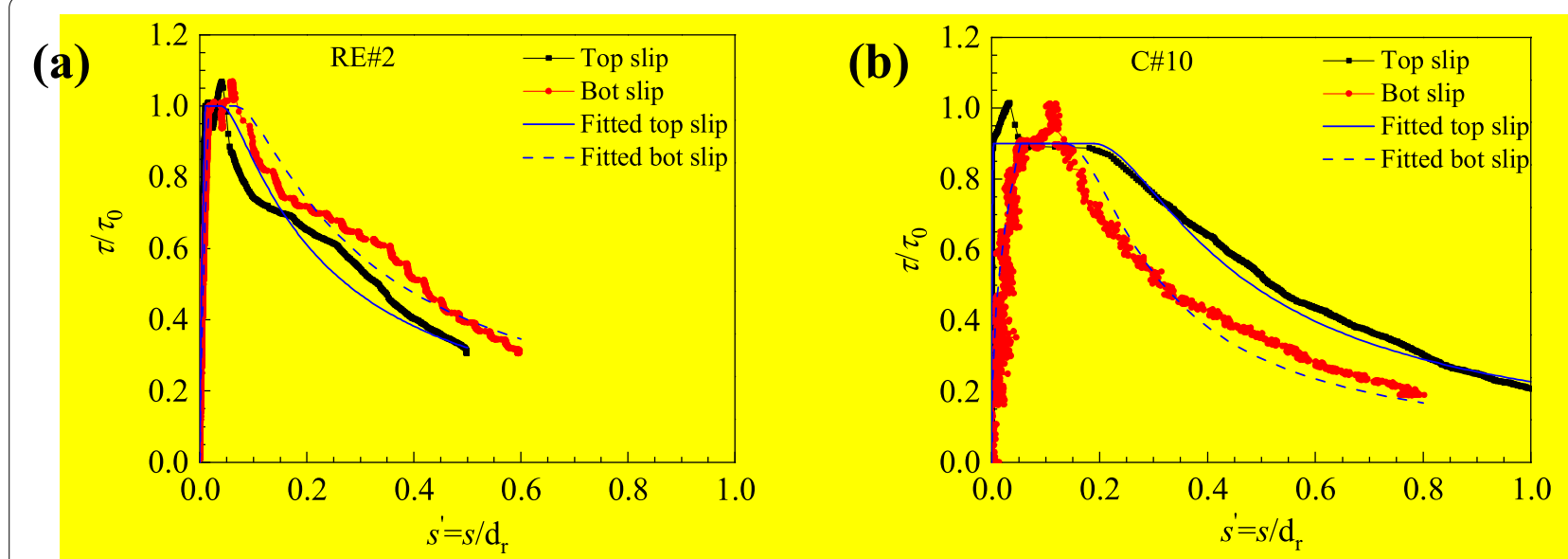

(c)

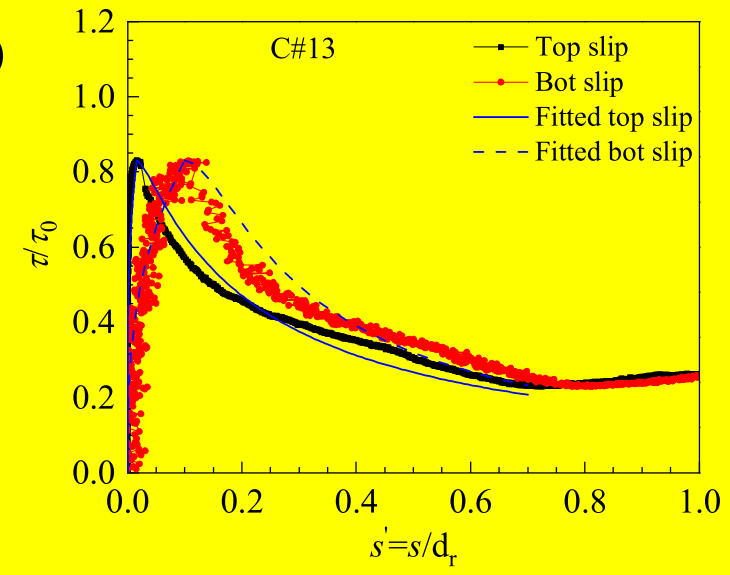

(d)

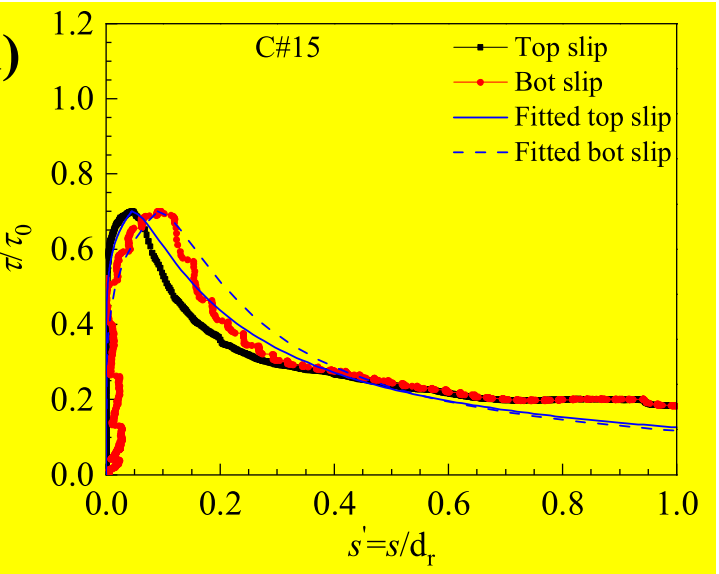

Fig. 14 Comparison of measured and fitted bond-slip curves with eq. (10) for specimen (a) RE\#2, (b) C\#10, (c) C\#13, and (d) C\#15

Table 4 Parameters extracted from bond-slip model

\begin{tabular}{|c|c|c|c|c|c|c|c|c|c|c|c|}
\hline \multirow[t]{2}{*}{ Specimen } & \multirow[t]{2}{*}{$\eta_{1}(\%)$} & \multirow[t]{2}{*}{$\eta_{2}(\%)$} & \multirow[t]{2}{*}{$\varphi$} & \multicolumn{3}{|c|}{ Top slip } & \multirow[b]{2}{*}{$s_{2}$} & \multicolumn{4}{|c|}{ Bottom slip } \\
\hline & & & & $a$ & $\beta$ & $s_{1}$ & & $a$ & $\beta$ & $s_{1}$ & $s_{2}$ \\
\hline RE\#2 & 0.0 & 0.0 & 1.00 & 0.60 & 5.0 & 0.010 & 0.040 & 0.70 & 4.0 & 0.017 & 0.067 \\
\hline RE\#3 & 0.0 & 0.0 & 1.00 & 0.60 & 3.0 & 0.010 & 0.040 & 0.65 & 2.8 & 0.027 & 0.077 \\
\hline C\#1 & 1.5 & 10.0 & 1.07 & 0.60 & 4.5 & 0.009 & 0.090 & 0.70 & 6.5 & 0.059 & 0.190 \\
\hline C\#3 & 2.2 & 11.2 & 0.80 & 0.60 & 4.5 & 0.002 & 0.140 & 0.62 & 6.0 & 0.023 & 0.230 \\
\hline C\#4 & 4.1 & 7.10 & 0.98 & 0.20 & 9.0 & 0.033 & 0.114 & 0.30 & 8.7 & 0.130 & 0.130 \\
\hline C\#5 & 7.1 & 11.8 & 1.10 & 0.30 & 8.0 & 0.002 & 0.057 & 0.40 & 8.0 & 0.040 & 0.160 \\
\hline C\#6 & 7.7 & 34.0 & 0.74 & 0.20 & 3.5 & 0.024 & 0.024 & 0.50 & 3.6 & 0.090 & 0.090 \\
\hline C\#7 & 7.8 & 40.0 & 0.74 & 0.10 & 2.5 & 0.030 & 0.030 & 0.20 & 3.0 & 0.095 & 0.095 \\
\hline C\#8 & 9.1 & 30.4 & 0.88 & 0.20 & 6.0 & 0.007 & 0.051 & 0.35 & 10 & 0.052 & 0.200 \\
\hline C\#9 & 10.3 & 37.5 & 0.67 & 0.25 & 5.0 & 0.014 & 0.190 & 0.35 & 5.0 & 0.033 & 0.240 \\
\hline C\#10 & 12.2 & 48.8 & 0.90 & 0.20 & 4.5 & 0.003 & 0.190 & 0.40 & 8.0 & 0.053 & 0.140 \\
\hline C\#11 & 15.6 & 58.4 & 0.60 & 0.40 & 2.5 & 0.002 & 0.002 & 0.60 & 4.8 & 0.150 & 0.150 \\
\hline C\#12 & 17.8 & 70.1 & 0.74 & 0.40 & 2.8 & 0.019 & 0.019 & 0.40 & 3.5 & 0.077 & 0.077 \\
\hline C\#13 & 18.1 & 71.2 & 0.83 & 0.25 & 4.5 & 0.016 & 0.016 & 0.35 & 5.0 & 0.100 & 0.100 \\
\hline C\#14 & 29.5 & 72.1 & 0.72 & 0.25 & 2.0 & 0.023 & 0.023 & 0.40 & 6.0 & 0.160 & 0.160 \\
\hline C\#15 & 35.0 & 90.4 & 0.70 & 0.12 & 5.0 & 0.045 & 0.045 & 0.20 & 6.0 & 0.090 & 0.090 \\
\hline
\end{tabular}


(a)

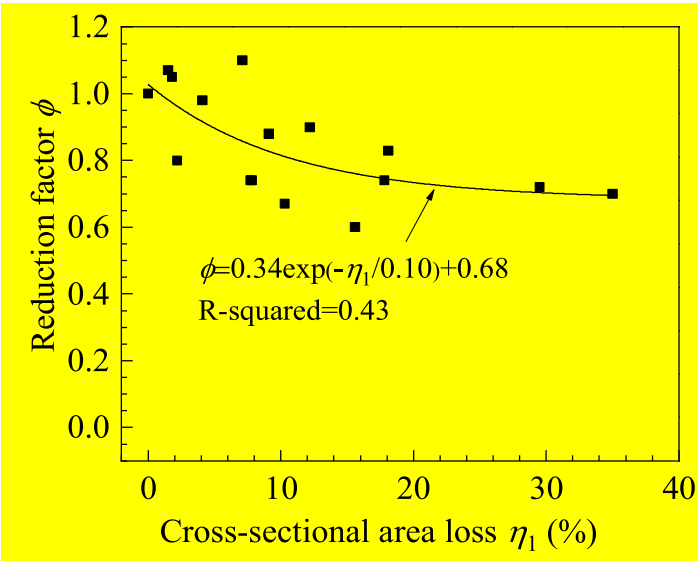

(b)

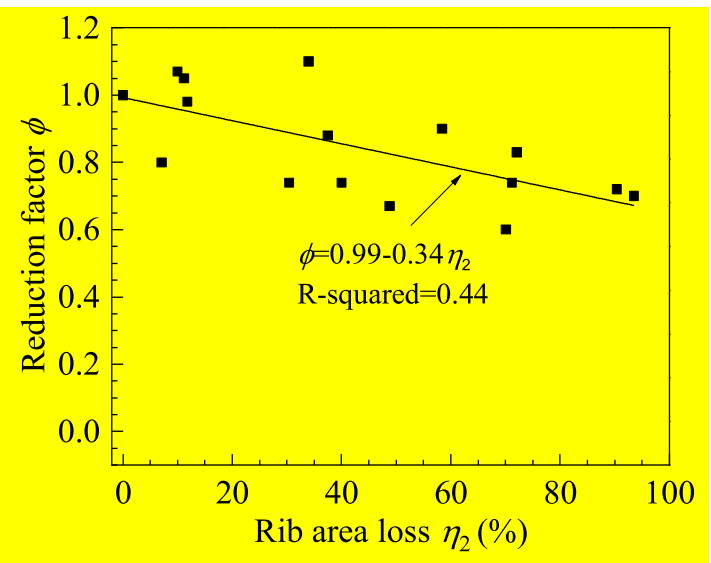

Fig. 15 Reduction factor as a function of (a) the average cross-sectional area loss, and (b) the rib area loss
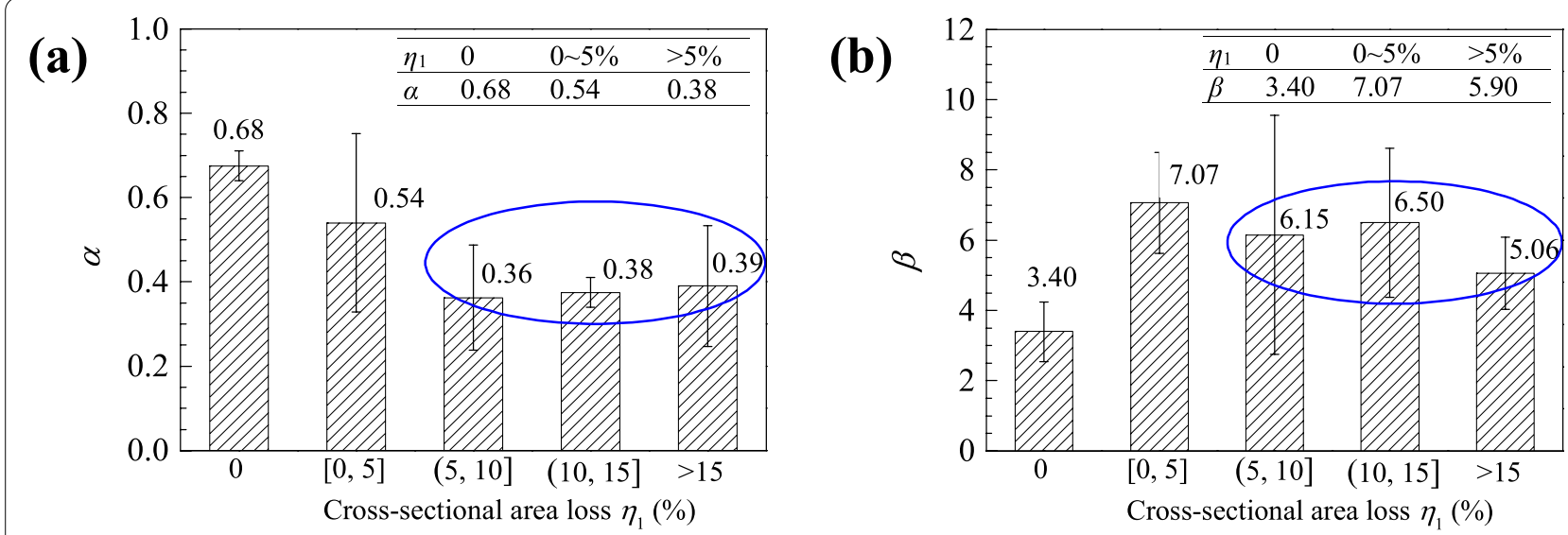

Fig. 16 Recommended parameter (a) $\alpha$ and (b) $\beta$ for engineering applications based on the average cross-sectional area loss and bottom slip

(2) The rib area loss of steel rebar exponentially increases as a function of the average cross-sectional area loss. The bond stress decreases with an increase of the average area loss, the rib area loss and the crack width on the surface of concrete specimens. Both the steel rebar slip difference between the top and bottom concrete faces and the average concrete crack width increase with an increase of both average area loss and rib area loss of steel rebars.

(3) Steel-concrete bond degradation depends on the average area loss, the number and width of concrete cracks. With less than $7 \%$ area loss and a narrower than $0.5 \mathrm{~mm}$ crack, the maximum bond is slightly increased due to increased confinement. With $7-12 \%$ area loss and two cracks with a total width of $0.5-1.5 \mathrm{~mm}$, the maximum bond strength decreases, but still show similar bond-slip curves with uncorroded specimens. With more than
$12 \%$ area loss and two or three cracks with a total width of greater than $1.5 \mathrm{~mm}$, the maximum bond strength decreases significantly and shows different bond-slip curves as those with uncorroded steel rebars.

(4) An empirical bond-slip model is developed and the corrosion effect on the model was taken into account by introducing a reduction factor. The reduction factor exponentially decreases with an increase of the average area loss, and linearly decreases as a function of rib area loss of steel rebars.

\section{Acknowledgements}

None

\section{Authors' contributions}

Tang F conceived and planned the experiments, prepared the samples and conducted accelerated corrosion tests and 3D laser scan; Tang F and Lin Z carried out the pullout tests; Qu H collected and analyzed the AE test data; 
Tang F, Lin Z, Qu H and Chen G contributed to the interpretation of the results. All authors provided critical feedback and helped shape the research, analysis and manuscript. The author(s) read and approved the final manuscript.

\section{Funding}

This work was supported by the National Natural Science Foundation of China (No. 52078099).

\section{Availability of data and materials}

Some or all data that support the findings of this study are available from the corresponding author upon reasonable request (load-slip curves, 3D scan data of corroded steel bar, and AE data).

\section{Declarations}

\section{Ethics approved and consent to participate}

Not applicable.

\section{Consent of publication}

Not applicable.

\section{Competing interests}

The authors declare that they have no competing interests.

\section{Author details}

${ }^{1}$ School of Civil Engineering, Dalian University of Technology, Dalian 116024, Liaoning, China. ${ }^{2}$ Department of Civil and Environmental Engineering, North Dakota State University, Fargo, ND 58018, USA. ${ }^{3}$ School of Civil Engineering, Tongji University, Shanghai 200092, China. ${ }^{4}$ Department of Civil, Architectural and Environmental Engineering, Missouri University of Science and Technology, Rolla, MO 65401, USA.

Received: 28 November 2021 Accepted: 24 February 2022 Published online: 07 March 2022

\section{References}

1. Wight JK, MacGregor JG (2011) (2011) reinforced concrete: mechanics and design, 6th edn. Prentice Hall, New Jersey

2. Bhargava K, Ghosh AK, Mori Y, Ramanujam S (2007) Corrosion-induced bond strength degradation in reinforced concrete-analytical and empirical models. Nucl Eng Des 237:1140-1157

3. Tang F, Chen G, Yi W (2014) Corrosion-induced concrete cracking, steelconcrete bond loss, and mechanical degradation of steel bars. Adv Mater Res 919:1760-1770

4. Zhao Y, Wu Y, Jin W (2013) Distribution of millscale on corroded steel bars and penetration of steel corrosion products in concrete. Corros Sci 66:160-168

5. Guzman S, Galvez JC, Sancho JM (2011) Cover cracking of reinforced concrete due to rebar corrosion induced by chloride penetration. Cem Concr Res 41:893-902

6. Shang H, Chai X (2021) Bond behavior between corroded steel bar and concrete under reciprocating loading history of beam type specimens. Eng Struct 247:113112

7. Stanish K, Hooton RD, Pantazonpoulou SJ (1999) Corrosion effects on bond strength in reinforced concrete. ACI Struct J 96:915-921

8. Chung L, Cho SH, Kim JHJ, Yi ST (2004) Correction factor suggestion for $\mathrm{ACl}$ development length provisions based on flexural testing of RC slabs with various levels of corroded reinforcing bars. Eng Struct 26:1013-1026

9. Abosrra $L$, Ashour AF, Youseffi M (2011) Corrosion of steel reinforcement in concrete of different compressive strength. Constr Build Mater 25:3915-3925

10. Yalciner $H$, Eren $O$, Sensoy S (2012) An experimental study on the bond strength between reinforcement bars and concrete as a function of concrete cover, strength and corrosion level. Cem Concr Res 42:643-655

11. Tang D, Molyneaux TKC, Law DW (2011) Gravina RInfluence of surface crack width on bond strength of reinforced concrete. ACI Mater J. 108:29-37
12. Law DW, Tang D, Molyneaux TKC, Gravina R (2011) Impact of crack width on bond: confined and unconfined rebar. Mater Struct 44:1287-1296

13. Lee $H$, Noguchi T, Tomosawa F (2002) Evaluation of the bond properties between concrete and reinforcement as a function of the degree of reinforcement corrosion. Cem Concr Res 32:1313-1318

14. Trezos KG, Sfikas IP, Pasios CG (2014) Influence of water-to-binder ratio on top-bar and on bond variation across length in self-compacting concrete specimens. Cem Concr Comp 48:127-139

15. Tondolo F (2015) Bond behavior with reinforcement corrosion. Constr Build Mater 93:926-932

16. Zhou H, Lu J, Xv X, Dong B, Xing F (2015) Effects of stirrup corrosion on bond-slip performance of reinforcing steel in concrete: an experimental study. Constr Build Mater 93:257-266

17. Lin H, Zhao Y (2016) Effects of confinements on the bond strength between concrete and corroded steel bars. Constr Build Mater 118:127-138

18. Wang X, Zhang W, Cui W, Wittmann FH (2011) Bond strength of corroded steel bars in reinforced concrete structural elements strengthened with CFRP sheets. Cement Concrete Comp 33:513-519

19. Law DW, Molyneaux TCK (2017) Impact of corrosion on bond in uncracked concrete with confined and unconfined rebar. Constr Build Mater 155:550-559

20. Zhao Y, Lin H, Wu L, Jin W (2013) Bond behavior of normal/recycled concrete and corroded steel bars. Constr Build Mater 48:348-359

21. Fernandez I, Etxeberria M, Mari AR (2016) Ultimate bond strength assessment of uncorroded and corroded reinforced recycled aggregate concretes. Constr Build Mater 111:543-555

22. Wu Y, Lv H, Zhou S, Fang Z (2016) Degradation model of bond performance between deteriorated concrete and corroded deformed steel bars. Constr Build Mater 119:89-95

23. Ma Y, Guo Z, Wang L, Zhang J (2017) Experimental investigation of corrosion effect on bond behavior between reinforcing bar and concrete. Constr Build Mater 152:240-249

24. Chung L, Kim JHJ, Yi ST (2008) Bond strength prediction for reinforced concrete members with highly corroded reinforcing bars. Cem Concr Comp 30:603-611

25. Choi YS, Li ST, Kim MY, Jung WY, Yang El (2014) Effect of corrosion method of the reinforcing bar on bond characteristics in reinforced concrete specimens. Constr Build Mater 54:180-189

26. Li F, Yuan Y (2013) Effects of corrosion on bond behavior between steel strand and concrete. Constr Build Mater 38:413-422

27. Davis M, Hoult NA, Scott A (2016) Distributed strain sensing to determine the impact of corrosion on bond performance in reinforced concrete. Constr Build Mater 114:481-491

28. Behnia A, Chai HK, Shiotani T (2014) Advanced structural health monitoring of concrete structures with the aid of acoustic emission. Constr Build Mater 65:282-302

29. Patil S, Karkare B, Goyal S (2017) Corrosion induced damage detection of in-service RC slabs using acoustic emission technique. Constr Build Mater 156:123-130

30. Yu A, Naqvi MW, Hu L, Zhao Y (2020) An experimental study of corrosion damage distribution of steel bars in reinforced concrete using acoustic emission technique. Constr Build Mater 254:119256

31. Goldaran R, Turer A (2020) Application of acoustic emission for damage classification and assessment of corrosion in pre-stressed concrete pipes. Measurement 160:107855

32. Steen CV, Pahlavan L, Wevers M, Verstrynge E (2019) Localization and characterisation of corrosion damage in reinforced concrete by means of acoustic emission and X-ray computed tomography. Constr Build Mater 197:21-29

33. Van Steen C, Verstrynge E, Wevers M, Vandewalle L (2019) Assessing the bond behavior of corroded smooth and ribbed rebars with acoustic emission monitoring. Cem Concr Res 120:176-186

34. Kshani MM, Crewe AJ, Alexander NA (2013) Use of a 3D optical measurement technique for stochastic corrosion pattern analysis of reinforcing bars subjected to accelerated corrosion. Corr Sci 73:208-221

35. Tang F, Lin Z, Chen G, Yi W (2014) Three-dimensional corrosion pit measurement and statistical mechanical degradation analysis of deformed steel bars subjected to accelerated corrosion. Constr Build Mater 70:104-117 
36. Li D, Wei R, Li L, Guan X, Mi X (2019) Pitting corrosion of reinforcing steel bars in chloride contaminated concrete. Constr Build Mater 199:359-368

37. Chauhan A, Sharma UK (2021) Crack propagation in reinforced concrete exposed to non-uniform corrosion under real climate. Eng Fract Mech 248:107719

38. Wu B, Yang Y, Zhang L, Wang Y, Li H (2020) Meso-scale numerical study on the non-uniform corrosion-induced cracking of confined concrete. Constr Build Mater 260:120463

39. Avadh K, Jiradilok P, Bolander JE, Nagai K (2021) Mesoscale simulation of pull-out performance for corroded reinforcement with stirrup confinement in concrete by 3D RBSM. Cem Concr Compos 116:103895

40. Wu C, Chiou Y (2019) Stress-strain response of cylindrical rubber fender under monotonic and cyclic compression. Materials 12:282

41. Wang L, Jin Y, Xia H, Fan L (2016) Experimental study of a pull-out test of corroded steel and concrete using the acoustic emission monitoring method. Constr Build Mater 122:163-170

42. Prince MJR, Singh B (2013) Bond behavior of deformed steel bars embedded in recycled aggregate concrete. Constr Build Mater 49:852-862

43. Zhang X, Dong W, Zheng J, Wu Z, Hu Y, Li Q (2014) Bond behavior of plain round bars embedded in concrete subjected to lateral tension. Constr Build Mater 54:17-26

44. Bompa DV, Elghazouli AY (2017) Bond-slip response of deformed bars in rubberized concrete. Constr Build Mater 154:884-898

\section{Publisher's Note}

Springer Nature remains neutral with regard to jurisdictional claims in published maps and institutional affiliations.

\section{Submit your manuscript to a SpringerOpen ${ }^{\circ}$ journal and benefit from:}

- Convenient online submission

- Rigorous peer review

- Open access: articles freely available online

- High visibility within the field

- Retaining the copyright to your article

Submit your next manuscript at $\gg$ springeropen.com 